\title{
Surface Energy Balance and Buoyancy Response to Shallow Cumulus Shading
}

\author{
FABIENNE LOHOU \\ Laboratoire d'Aérologie, Université de Toulouse, Toulouse, France \\ EDWARD G. PATTON \\ National Center for Atmospheric Research,* Boulder, Colorado
}

(Manuscript received 16 May 2013, in final form 8 October 2013)

\begin{abstract}
The interactions surrounding the coupling between surface energy balance and a boundary layer with shallow cumuli are investigated using the National Center for Atmospheric Research's large-eddy simulation code coupled to the Noah land surface model. The simulated cloudy boundary layer is based on the already well-documented and previously simulated 21 June 1997 case at the Atmospheric Radiation Measurement Southern Great Plains central facility. The surface energy balance response to cloud shading is highly nonlinear, leading to different partitioning between sensible and latent heat flux compared to the surface not impacted by cloud. The evaporative fraction increases by about $2 \%-3 \%$ in the presence of shallow cumuli at the regional scale but can increase by up to $30 \%$ at any individual location. As expected, the cloud's reduction of solar irradiance largely controls the surface's response. However, the turbulence and secondary circulations associated with the cloud dynamics increases the surface flux variability. Even though they are less than $1 \mathrm{~km}$ in horizontal scale, the cloud-induced surface heterogeneities impact the vertical flux of heat and moisture up to approximately $20 \%$ of the height of the subcloud layer $z_{\mathrm{sl}}$, higher than the surface layer's typical extent. Above $0.2 z_{\mathrm{sl}}$, the cloud root tends to amplify the drying and the cooling of the subcloud layer. Near the entrainment zone, the cloud-induced latent heat flux increase and sensible heat flux decrease compensate each other with respect to total buoyancy and therefore do not significantly modify the subcloudlayer entrainment rate over large time scales.
\end{abstract}

\section{Introduction}

Because of their relatively small size and radiative impact and their tendency not to produce rain, shallow cumulus clouds have received little attention within the scientific community than the myriad of other cloud forms (i.e., stratocumulus, deep precipitating convection, etc.) (Stevens 2005). A significant portion of cloud research that has occurred has focused on understanding and parameterizing the transport and mixing associated with shallow cumulus and their roots within the subcloud layer (e.g., LeMone and Pennell 1976; Nicholls and LeMone 1980; Nicholls et al. 1982; Tiedtke et al.

\footnotetext{
* The National Center for Atmospheric Research is sponsored by the National Science Foundation.

Corresponding author address: Fabienne Lohou, Laboratoire d'Aérologie, Université de Toulouse, 8 route de Lannemezan, 65300 Campistrous, France.

E-mail: fabienne.lohou@aero.obs-mip.fr
}

1988; Siebesma 1998; Brown et al. 2002; Soares et al. 2004; Bellon and Stevens 2005; Zhao and Austin 2005a,b; Stevens 2007; Bretherton and Park 2008; Heus and Jonker 2008; Stechmann and Stevens 2010). However, even though the impact of cumulus convection on surface fluxes has been shown to significantly affect larger-scale circulations (Betts and Ridgway 1988) and the skill of medium-range weather forecasts (Tiedtke 1989), the coupling between shallow cumulus and the land surface deserves further analysis. Without focusing specifically on shallow cumuli, some recent investigations (e.g., Small and Kurc 2003; Gentine et al. 2011a; Bateni and Entekhabi 2012) provide clues into the role of broader cloud types on the surface energy balance. A more complete approach is provided by Gentine et al. (2011b), who used an analytical linear model of the soilvegetation-ABL continuum (Gentine et al. 2010) to study the spectral state of this continuum response to different radiative forcing harmonics.

Ascertaining the impact of shallow cumulus clouds on surface fluxes using in situ observations is extremely 
difficult because their duration can be relatively short. Factors affecting this duration include 1) the short lifetimes ( $\sim 10 \mathrm{~min})$ of individual clouds, 2$)$ the small horizontal scales $(\sim 1 \mathrm{~km})$ of the clouds, and 3$)$ the potentially short time which any particular cloud spends overhead. We therefore turn to turbulence-resolving calculations.

Large-eddy simulation (LES) largely began with Deardorff (1970) and has progressed over the last few decades to become an important complement to outdoor observations. Most LES studies of cloudy boundary layers have focused on the cloud response to variations in imposed surface forcing (e.g., Nicholls et al. 1982; Lewellen and Lewellen 1996; Moeng 1998, 2000; Brown et al. 2002; Lewellen and Lewellen 2002; Siebesma et al. 2003; Zhu and Albrecht 2003; Stevens 2007). Although a few researchers have investigated low clouds using turbulence-resolving calculations with coupled land surfaces (e.g., Deardorff 1980; Golaz 2001; Jiang and Feingold 2006; Huang and Margulis 2011, 2013), these efforts mainly focused on the cloud response to spatially varying surface forcing. Although Schumann et al. (2002) studied the impact of fair-weather shallow convection over dry land surfaces and the impact of a nonzero solar zenith angle, little effort has focused on the local surface response to shallow cumulus passing overhead.

Using a similar toolset as Deardorff (1980), Golaz (2001), and Jiang and Feingold (2006) but using Brown et al.'s (2002) initial conditions and forcing as our basis (where the case's details are described in section 2), we investigate the interactions surrounding the coupling between shallow cumulus and the land surface. The critical interactions are depicted in Fig. 1 and define the outline of this paper.

Passing shallow cumulus clouds briefly and intermittently reduce the solar irradiance. The surface responds by rapidly adjusting the balance between sensible, latent, and soil heat flux. The average and local surface response are both investigated in section 3 (Fig. 1, point I). Three processes likely modify the surface energy balance (SEB) in the following ways: 1) reducing the incoming solar radiation, 2) modifying the surface fluxes resulting from cloud-induced atmospheric turbulence and generating secondary circulations, and 3) warming and drying the boundary layer by entrainment of freetropospheric air into the boundary layer, which alters the SEB by modifying temperature and moisture gradients between the atmosphere and the skin surface. Section 4 investigates the relative importance of cloudinduced solar irradiance versus turbulence modification on the SEB (Fig. 1, point II). The atmospheric boundary layer's response to cloud-induced surface flux heterogeneity is discussed in section 5 [where section $5 \mathrm{a}$ examines buoyancy fluxes in the cloud roots (here defined

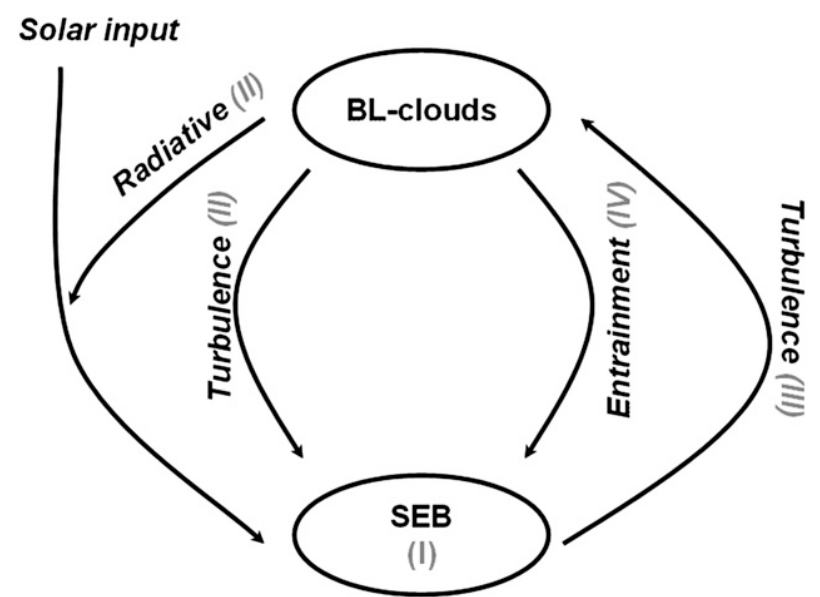

FIG. 1. Interactions involved in the coupling between the surface energy balance (SEB) and boundary layer (BL) clouds. Point I: the average and local surface response to shallow cumulus. Point II: the effects of decreasing solar input and cloud-induced turbulence on the SEB. Point III: the boundary layer's response to cloud-induced surface heterogeneity. Point IV: entrainment at boundary layer top with shallow cumulus. Note that the numbers I-IV simply mark different processes/interactions and do not imply any particular order of importance.

as the subcloud column; Fig. 1, point III) and section $5 b$ examines the influence on entrainment (Fig. 1, point IV)], and section 6 summarizes the results and presents some concluding remarks.

\section{Coupled model and case description}

The simulated case is based on observations from the Atmospheric Radiation Measurement (ARM) Southern Great Plains (SGP) central facility on 21 June 1997. The initial atmospheric conditions come from those defined for Brown et al.'s (2002) large-eddy simulation intercomparison study. In the Brown et al. (2002) study, initial profiles of potential temperature $\theta$, total water mixing ratio $r_{v}$, and horizontal winds were prescribed at 0530 local solar time (LST), corresponding to 1130 UTC. To account for significant cooling between 0530 and 0730 LST (not accounted for in the large-scale forcings) and to prevent clouds from reaching the top of the simulated domain, the initial $\theta$ and $r_{v}$ profiles were slightly modified compared to those observed (Brown et al. 2002; these initial profiles are presented in Figs. $3 \mathrm{c}$ and $3 \mathrm{~d}$ ). The horizontal wind profiles are initially constant with height $\left(u=10 \mathrm{~m} \mathrm{~s}^{-1}\right.$ and $\left.v=0 \mathrm{~m} \mathrm{~s}^{-1}\right)$, and a $10 \mathrm{~m} \mathrm{~s}^{-1}$ westerly geostrophic wind is imposed throughout the simulation. Large-scale heat and moisture advection follow those described by Brown et al. (2002).

In the simulation discussed here, Brown et al.'s (2002) imposed surface heat and moisture fluxes are replaced 
by coupling the atmospheric large-eddy simulation with an interactive land surface model (Patton et al. 2005), where a separate implementation of the Noah land surface model [slightly modified from Noah, version 2.7.1, for application to turbulence-resolving studies; for details, see Patton et al. (2005)]) at every horizontal grid point at the bottom of the three-dimensional (3D) turbulence-resolving atmospheric simulation uses a one-dimensional soil representation to solve an energy balance driven by the instantaneous overlying wind, temperature, and humidity to determine the local instantaneous surface momentum, heat, and moisture fluxes.

The coupling between Noah and the LES is implemented such that at every surface grid point, the surface heat fluxes (sensible, latent, and soil) instantly balance the available energy (net radiation). The surface skin temperature is therefore diagnosed from the soil heat flux (solved using a diffusion equation) and reacts immediately to the rapidly changing cloudy boundary layer forcing.

Horizontally homogeneous initial soil temperature and soil moisture content (SMC) profiles are generated by running the one-dimensional High-Resolution Land Data Assimilation System (HRLDAS; Chen et al. 2007) for a 6-month period, where initial SGP observed soil temperature and moisture content profiles evolve within HRLDAS driven by 6 months of SGP-observed 2-m atmospheric forcings (atmospheric winds, temperature and specific humidity, precipitation, and downward longwave and solar irradiance). This process allows 1) the land surface model (LSM) to equilibrate with the forcing and 2) selection of the soil and vegetation types that best reproduce the ARM SGP soil temperature, moisture, and surface flux measurements. It is important to note that this study does not aim to perfectly reproduce the ARM SGP surface flux observations but rather to lean on realistic conditions when studying the interactions between shallow clouds and the underlying land surface.

The parameter combinations generating the best agreement between the HRLDAS-simulated and the SGP-observed fluxes during the 6-month period included a clay-loam soil type with a volumetric soil moisture wilting point $\left(\mathrm{SMC}_{\mathrm{wp}}\right)$ and field capacity $\left(\mathrm{SMC}_{\mathrm{fc}}\right)$ of 0.103 and $0.382 \mathrm{~m}^{3} \mathrm{~m}^{-3}$, respectively, and a nontranspiring grass vegetation type with an albedo of 0.2 and a roughness length of $0.08 \mathrm{~m}$. Initial vertical profiles of soil temperature and moisture (Table 1) were selected from the 6-month HRLDAS simulation when both surface flux and atmospheric conditions were in close agreement to those observed on 21 June 1997. The soil moisture index (SMI) is defined as
TABLE 1. Initial vertical profiles of soil temperature and soil moisture content.

\begin{tabular}{ccc}
\hline \hline LSM level $(\mathrm{m})$ & Temperature $(\mathrm{K})$ & SMC $\left(\mathrm{m}^{3} \mathrm{~m}^{-3}\right)$ \\
\hline 0.05 & 298.28 & 0.441 \\
0.20 & 298.00 & 0.419 \\
0.60 & 293.73 & 0.338 \\
1.00 & 290.92 & 0.348 \\
\hline
\end{tabular}

$$
\mathrm{SMI}=\frac{\mathrm{SMC}-\mathrm{SMC}_{\mathrm{wp}}}{\mathrm{SMC}_{\mathrm{fc}}-\mathrm{SMC}_{\mathrm{wp}}} ;
$$

at initialization, SMI in the uppermost $5 \mathrm{~cm}$ equals 0.93 . Therefore, the initial soil conditions are horizontally homogeneous, but the soil temperature and moisture conditions at every horizontal location freely evolve based on local atmospheric demand.

The simulation resolves a $10.24 \times 10.24 \mathrm{~km}^{2}$ horizontal domain extending vertically to $4.096 \mathrm{~km}$ resolved by $512^{3}$ grid points, thereby implying horizontal and vertical grid resolutions of 20 and $8 \mathrm{~m}$, respectively. This resolution clearly satisfies the requirements outlined by Sullivan and Patton (2011) to produce resolution independent solutions for dry convective PBLs, and the domain size is 10 times larger than the simulated largest cloud diameter $(\sim 1 \mathrm{~km})$. The soil is resolved by four layers whose bottom limits are $[0.05,0.2,0.6,1] \mathrm{m}$. The simulation lasts $7.5 \mathrm{~h}$, beginning at $0530 \mathrm{LST}$ and ending at 1300 LST with a time step determined by a CourantFreidrichs-Lewy (CFL; Courant et al. 1967) number of 0.5 . After an initial period during which the turbulence develops, the time step averaged approximately $0.5 \mathrm{~s}$.

The solar irradiance evolves with time of day during the simulation, but the radiation scheme is one dimensional, meaning that the sun appears to always be located directly overhead but the sun's intensity varies with time of day. Therefore, clouds always shade the surface directly beneath. Schumann et al. (2002) showed that cloud-shading asymmetries associated with nonzero solar zenith angles has only limited impact on the turbulent motions, so this simplification should not drastically impact the results.

Following Joseph et al. (1976), the cloud's transmissivity $t_{c}$ is a function of the cloud's optical depth $\tau$ and a scattering phase function asymmetry factor $f$ (equal to 0.86 for the boundary layer cloud particle size under study), such that

$$
t_{c}=\frac{5-e^{-\tau}}{4+3 \tau(1-f)}
$$

where $\tau$ is calculated assuming a constant droplet effective radius $r_{e}$ of $10^{-5} \mathrm{~m}$ using the expression given by Stephens (1984), 

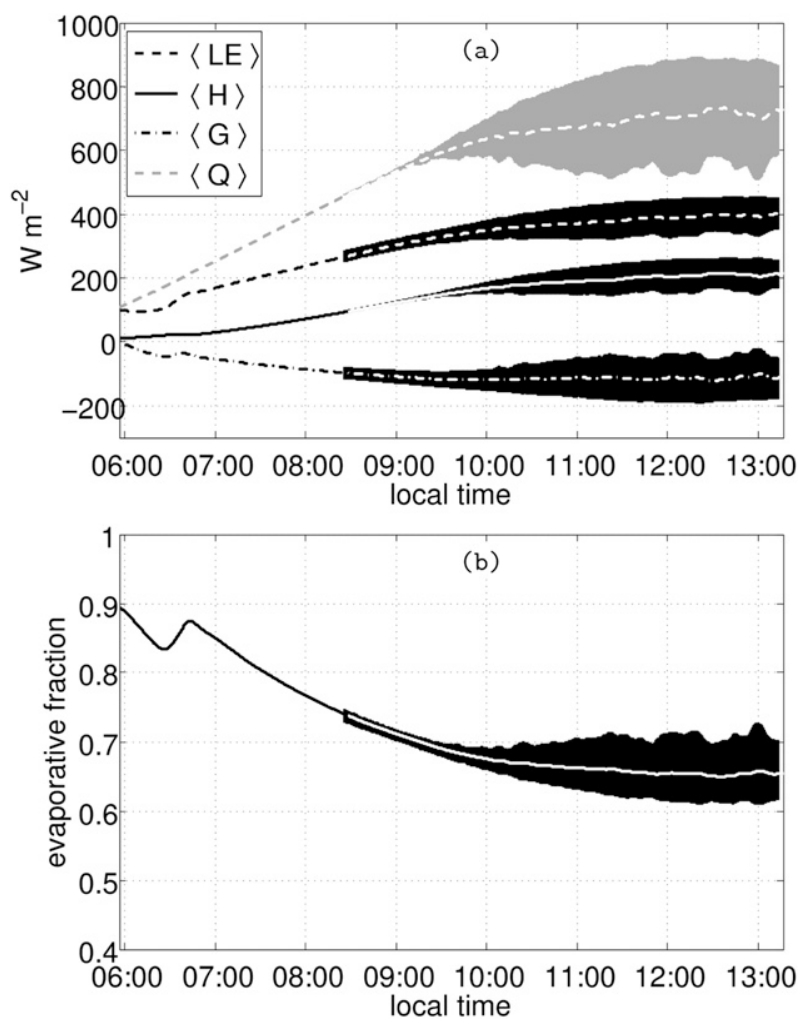

FIG. 2. Temporal evolution of the horizontal average (lines) and standard deviation (shaded areas) of (a) surface energy balance terms ( $\langle\mathrm{LE}\rangle,\langle H\rangle,\langle G\rangle$, and $\langle Q\rangle)$ and (b) evaporative fraction $(\langle\mathrm{EF}\rangle)$ as simulated by the National Center for Atmospheric Research (NCAR) LES code coupled to the Noah LSM for conditions similar to those described by Brown et al. (2002).

$$
\tau=\frac{3}{2} \frac{\mathrm{LWP}}{r_{e} \rho_{l}},
$$

where liquid water path (LWP) is in kilograms per square meter and the water density $\rho_{l}$ is in kilograms per cubic meter.

For any field variable $\psi$, turbulent fluctuations of that variable $\psi^{\prime}$ are defined as deviations from the instantaneous horizontal mean $\langle\psi\rangle$. In addition, to obtain quasi-stationary statistics, some quantities are also time averaged over a simulated hour. For simplicity, the angle bracket notation will also occasionally be used to represent this combined horizontal- and time-averaging process (e.g., Figs. 3, 4, 14).

The horizontal average and standard deviation of the surface energy balance terms (net radiation $Q$, sensible heat flux and latent heat flux $H$ and LE, the soil heat flux $G$, and the evaporative fraction EF) calculated by the LSM are presented in Fig. 2 between 0600 and 1300 LST. After the clouds begin to form (starting between 0900 and 1000 LST), the cloud shading clearly impacts the net radiation $\langle Q\rangle$ throughout the rest of the simulation (depicted by the $\langle Q\rangle$ 's flattening and the oscillating behavior of the horizontal average and by $\langle Q\rangle$ 's $150 \mathrm{~W} \mathrm{~m}^{-2}$ standard deviation). At noon, $\langle H\rangle$ and $\langle\mathrm{LE}\rangle$ are about 200 and $400 \mathrm{~W} \mathrm{~m}^{-2}$, respectively, compared to 140 and $500 \mathrm{~W} \mathrm{~m}^{-2}$ in Brown et al. (2002). $\langle\mathrm{EF}\rangle$ decreases from 0.9 to 0.65 throughout the simulation and its 0.05 standard deviation after 1100 LST indicates the highly fluctuating local values, which can range from 0.5 to 0.8 .

Figure 3 presents the evolution of horizontal- and 1-haveraged vertical profiles of the horizontal wind speed $\langle U\rangle$ and direction $\langle\phi\rangle$, potential temperature $\langle\theta\rangle$, and the water vapor mixing ratio $\left\langle r_{v}\right\rangle$. The horizontal wind speed rapidly homogenizes in the mixed layer (at about $7-8 \mathrm{~m} \mathrm{~s}^{-1}$ ) and exhibits strong wind shear in the surface layer and at the boundary layer top, as well as after 0900 LST in the cloud layer. The simulation's imposed geostrophic wind is westerly at all heights but, in response to Coriolis turning and surface drag, the horizontal winds veer about $15^{\circ}$ by the end of the simulation. Between 0600 and $1300 \mathrm{LST}$, the mean potential temperature in the mixed layer increases by $5.5 \mathrm{~K}$. Despite significant surface evaporation (as quantified by $\langle\mathrm{LE}\rangle$ in Fig. 2), the water vapor mixing ratio increases only $1 \mathrm{~g} \mathrm{~kg}^{-1}$ over the same time frame, which illustrates the drying of the wellmixed boundary layer by entrainment of dry air from aloft occurring both at that PBL top and within the cloud layer. Prior to the onset of clouds, the buoyancy flux profile (Fig. 4) follows the expected -0.2 ratio of the entrainment to surface buoyancy flux found in clear convective boundary layers (Deardorff et al. 1980). With the onset of clouds, a positive buoyancy flux develops above the mixed layer induced by latent heat release in the cloudy updrafts (e.g., Nicholls et al. 1982; Gentine et al. 2013). The cloud layer's development can be characterized through the horizontally averaged cloud fraction (i.e., the fraction of the surface shaded by cloud), the horizontally averaged liquid water path $\langle\mathrm{LWP}\rangle$ (i.e., the average amount of liquid water between cloud base and cloud top), and the cloud base and top shown in Fig. 5. The cloud base and top are defined by the lowest and highest nonzero values of the mean liquid water profile. From 0800 to 0900 LST, the cloud base and summit are defined but are not reliable since the liquid water path and the cloud fraction remain negligible. The height of the minimum horizontally averaged buoyancy flux $\left\langle z_{\mathrm{sl}}\right\rangle$ is also depicted in Fig. 5. After 0900 LST, $\left\langle z_{\mathrm{sl}}\right\rangle$ and the cloud base match well; the layer beneath $\left\langle z_{\mathrm{sl}}\right\rangle$ will be referred to as the subcloud layer.

According to Stull (1988) and Otles and Young (1996), shallow cumuli can be divided into three categories: passive, forced, and active cumuli. Forced cumuli never reach the level of free convection and remain dependent on thermal convection in the subcloud layer. 

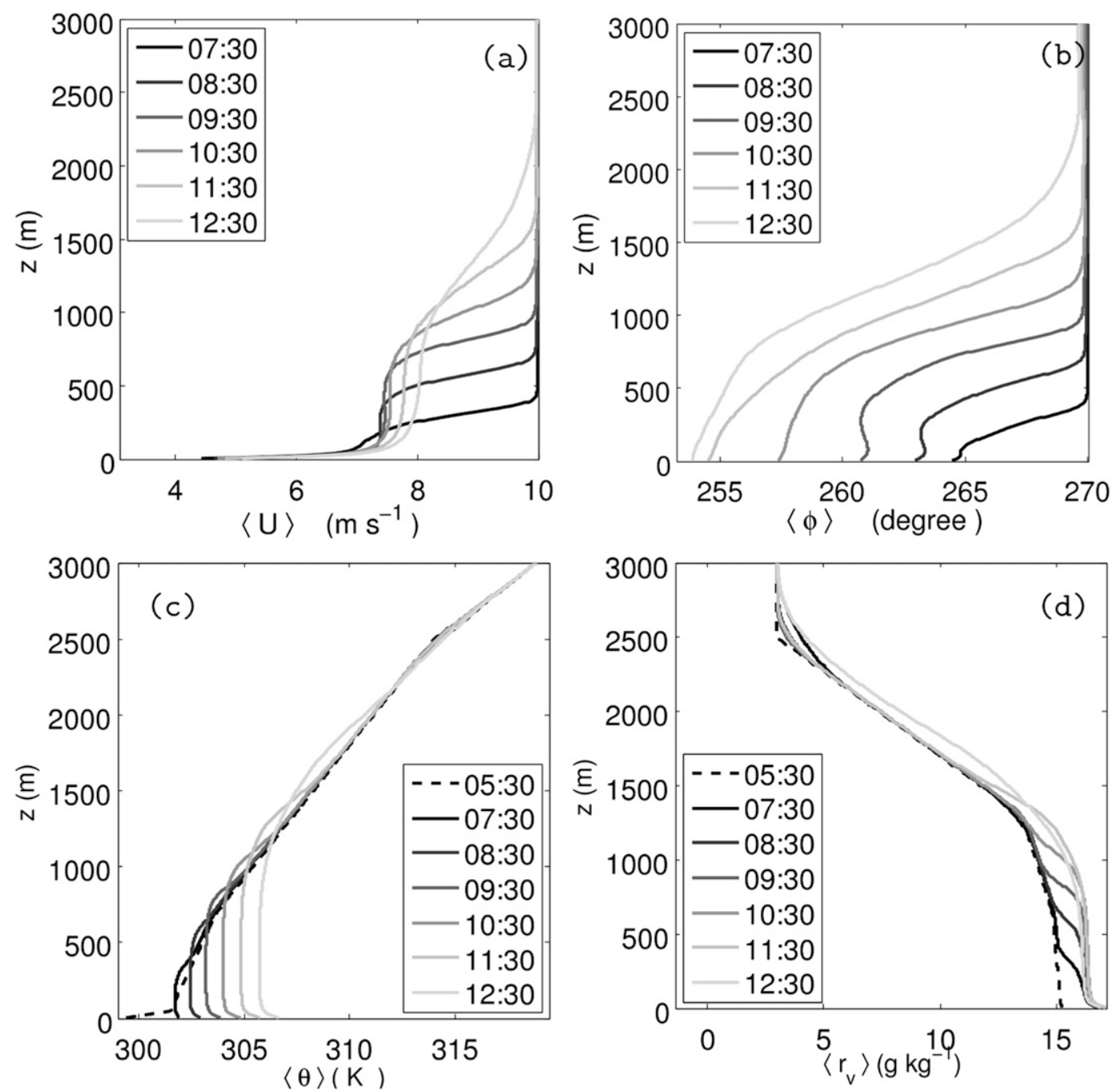

FIG. 3. Horizontal- and time-averaged vertical profiles of (a) horizontal wind $\langle U\rangle$, (b) wind direction $\langle\phi\rangle$, (c) potential temperature $\langle\theta\rangle$, and (d) water vapor mixing ratio $\left\langle r_{v}\right\rangle$ between 0730 and $1230 \mathrm{LST}$. The time averaging involves a 1-h average centered at the time (LST) noted in the legend. The initial vertical profiles of $\langle\theta\rangle$ and $\left\langle r_{v}\right\rangle$ at 0530 LST are included in (c) and (d), respectively.

Their diameter, vertical development, and cloud fraction are generally smaller than active cumuli. Active cumuli reach the level of free convection and develop their own circulations, initiating new thermals independent of the originating thermal (Zhao and Austin 2005a). In the current simulation, the clouds are positively buoyant above their level of free convection after 1030 LST (Fig. 4) and can be considered as active cumuli with $20 \%-30 \%$ cloud fraction and with vertical development to $1.5 \mathrm{~km}$ at $1300 \mathrm{LST}$ (Fig. 5).

\section{Surface response to boundary layer clouds}

Land surface response to shallow cumuli is poorly documented. Yet climate models rely on properly handling cloud-surface interactions for their lower boundary condition. When using 40-yr European Centre for Medium-Range Weather Forecasts (ECMWF) ReAnalysis (ERA-40) data to study the connection between cloud fields and both surface and large-scale atmospheric processes for Mississippi River subbasins, Betts (2007) noted that misrepresenting these couplings can act as a critical source of uncertainty in climate prediction. Identifying impacts of shallow clouds on surface fluxes experimentally usually leads to highly fluctuating fluxes because cloud shading tends to last only for short periods $(\leq 10 \mathrm{~min}$ ) within a $20-30$-min average, making robust statistics difficult to obtain.

The combination of 1) the land surface coupling in our simulation and 2) the simulation domain's horizontal 


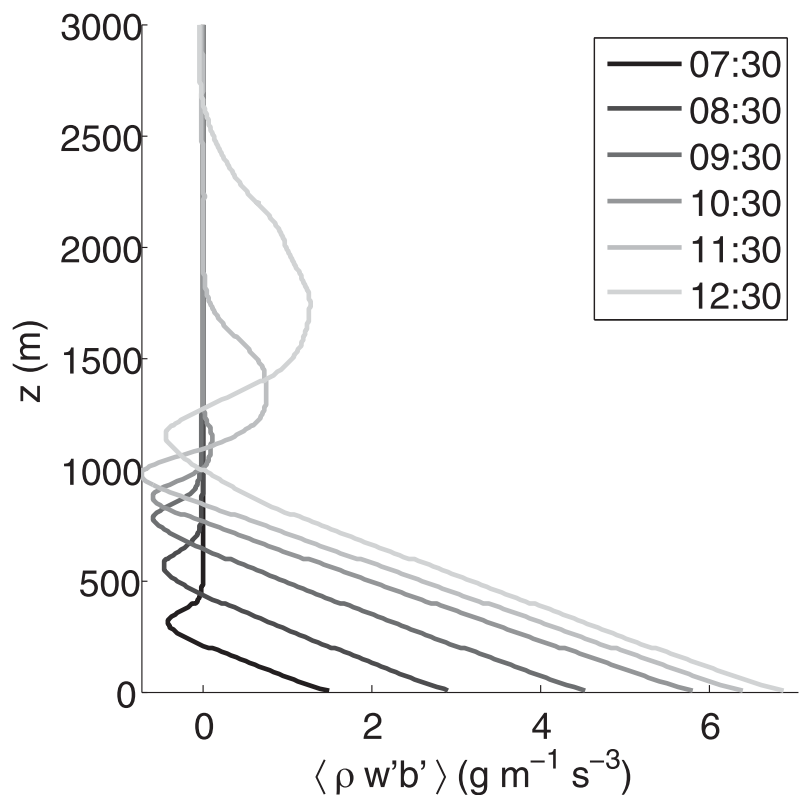

FIG. 4. Time evolution of the profile of horizontal- and timeaveraged buoyancy flux $\left(\mathrm{g} \mathrm{m}^{-1} \mathrm{~s}^{-3}\right)$. The time averaging involves a 1-h average centered at the time (LST) noted in the legend.

extent, which permits numerous clouds at any given time, allows investigation of shallow clouds' impact on the SEB in two ways: 1) in a horizontally averaged sense and 2) from a local instantaneous point of view. Analyzing the results in an average sense provides information on the large-scale (or net) impact of cloud shading and surface forcing at regional scales, whereas analyzing the results locally provides information on the surface's ability to react to short-duration variations in solar irradiance and to atmospheric fluid dynamics generated by the clouds and mimics instantaneous eddy covariance measurements.

\section{a. Average surface response}

\section{1) Coupled LES Results}

To properly quantify the effect of shallow clouds on the continental SEB, a comparison would be necessary of two very similar boundary layers, with and without cloud. Such a comparison is difficult to perform since clouds are dynamically and thermodynamically active in PBL processes. Preventing cloud formation in the LES would require dramatic changes to the PBL characteristics, therefore making the two boundary layers incomparable. So, in this study, solely a cloudy simulation is used, where it is assumed that, because the simulation never reaches beyond a $30 \%$ cloud fraction (Fig. 5a), the terms in the energy balance from the $70 \%$ of the area that is unshaded sufficiently mimics the surface fluxes in a noncloudy boundary layer. This assumption presumes
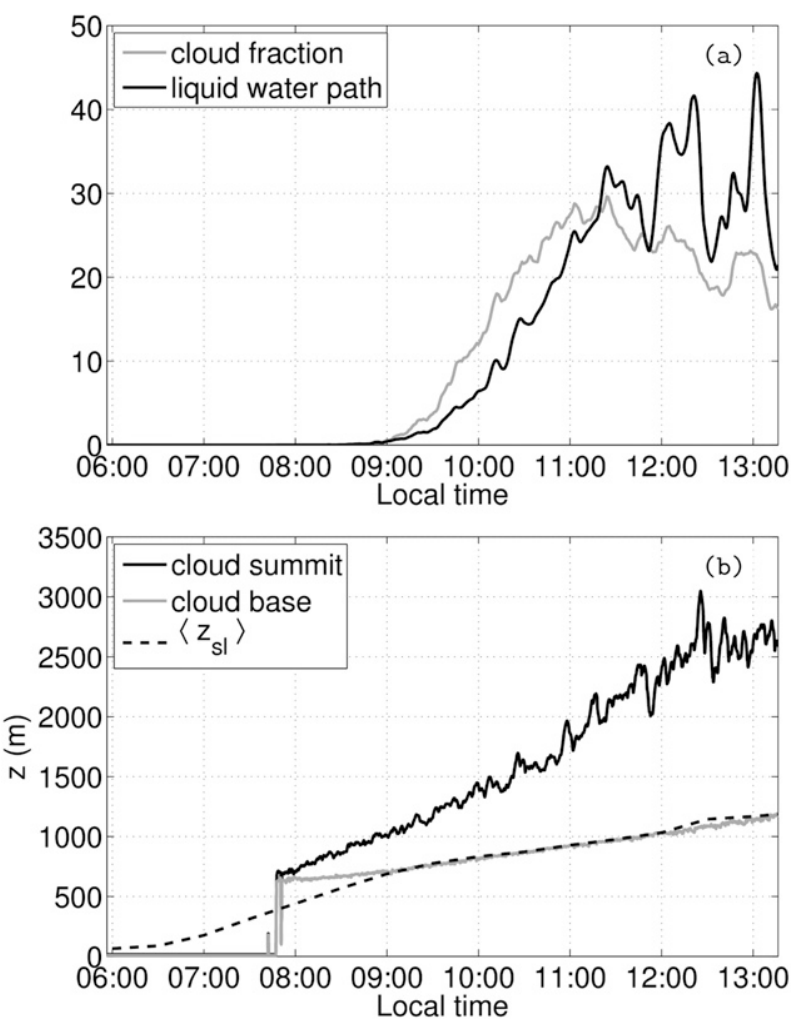

FIG. 5. Temporal evolution of the horizontally averaged (a) cloud fraction (\%) and liquid water path $\left(\mathrm{g} \mathrm{m}^{-2}\right)$ and (b) cloud base, cloud top, and the height of the horizontally averaged buoyancy flux minimum.

a priori that clouds more strongly impact surface fluxes through radiation than through exchange coefficient modifications. This point will be further analyzed in section 4.

Figure 6 presents the temporal evolution of the SEB terms ( $H, \mathrm{LE}, G$, and $Q)$ in the presence of shallow clouds (i.e., horizontally averaged over the entire domain) compared to without clouds (horizontally averaged solely over the unshaded area). This ratio quantifies how the various terms in the energy balance respond to the cloud-induced reduction in $Q$. At 0900 LST, the ratio for all SEB terms is $100 \%$ since the clouds have not yet developed. With increasing cloud fraction and the deepening of the cloud layer, every term in the SEB diminishes to below $100 \%$. Between 0900 and 1200 LST, $Q$ decreases by about $10 \%$, which leads to a $10 \%$ and $5 \%$ decrease of $H$ and LE, respectively. The soil heat flux $G$ decreases more than the other SEB terms (by about $20 \%$ ). Notice that the nonlinear response of the surface leads to a different reduction for each of the SEB terms. As a consequence, $\mathrm{EF}=\mathrm{LE} /(H+\mathrm{LE})$ increases by about $2 \%-3 \%$ in the cloudy boundary layer relative to the cloud-free boundary. Gentine et al. (2011a) shows 


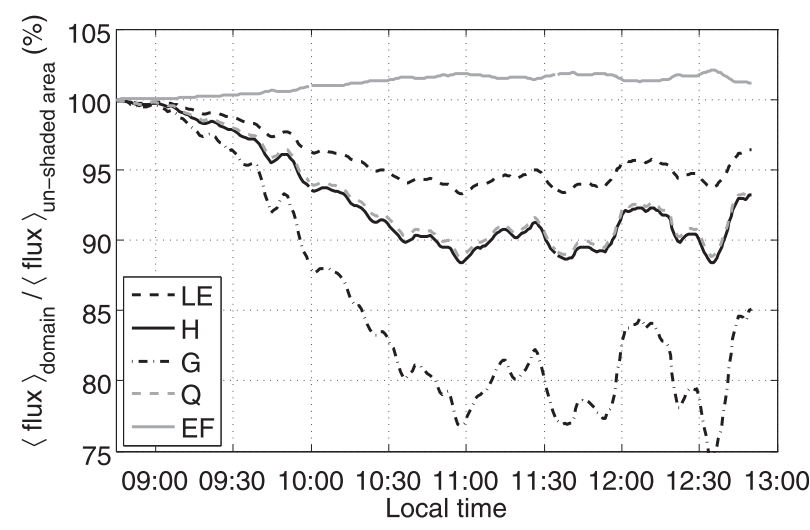

FIG. 6. Temporal evolution of SEB terms (LE, $H, G$, and $Q$ ) and EF averaged over the domain and normalized by each term's value averaged only over the area not shaded by clouds (i.e., the unshaded area). The values are presented in percentage.

a similar EF increase when their linear land surface model reacts to decreasing solar irradiance, as does Urankar et al. (2012) when analyzing Modern-Era Retrospective Analysis for Research and Applications (MERRA) data over India. Although research has shown that cloud cover can alter vegetative controls on energy partitioning through modifying the relative magnitudes of direct and diffuse radiation (e.g., Wang et al. 2008), the current simulation's grass canopy does not transpire and therefore cloud influences on transpiration do not participate in this EF increase.

\section{2) OFFLINE RESUlts}

To establish how this result depends on soil type and soil moisture, simulations using the one-dimensional version of the Noah LSM (i.e., uncoupled from the LES) responding to a $10 \%$ solar irradiance reduction are investigated for three different soil types and for widely ranging SMI. In these offline tests, the soil temperature profile, vegetation type, albedo, and roughness length all remain the same as those used in the coupled large-eddy simulation. The soil moisture variations are generated by multiplying the soil moisture profile described in Table 1 by a factor ranging from 0.2 to 1.3 at all levels. Adding to the clay-loam soil type used in the coupled large-eddy simulation, loam and clay soil types are chosen for their different values of $\mathrm{SMC}_{\mathrm{wp}}$ and $\mathrm{SMC}_{\mathrm{fc}}\left(\mathrm{SMC}_{\mathrm{wp}}=\right.$ $0.066,0.103$, and 0.138 and $\mathrm{SMC}_{\mathrm{fc}}=0.329,0.382$, and 0.412 for loam, clay-loam, and clay, respectively).

These one-dimensional land surface simulations are forced initially by the atmospheric conditions from the large-eddy simulation's lowermost level ( $4 \mathrm{~m}$ ) from 0600 to 1300 LST. Then, at 1300 LST, a constant solar irradiance drives the offline LSM for $20 \mathrm{~min}$. The solar irradiance is then reduced by $10 \%$ and held constant for an additional $20 \mathrm{~min}$. The surface immediately reacts to the solar irradiance variation and the SEB terms remain nearly constant during both 20 -min periods. The $H$, LE, and $G$ values averaged over the two 20 -min periods are presented as a function of soil moisture index for clayloam soil type in Fig. 7a. The SMI variation ranging from 0.5 to 0.9 allows $H$ and LE to vary between 150 and $400 \mathrm{~W} \mathrm{~m}^{-2}$. As expected, the flux partitioning favors evaporation when the SMI $>0.7$, whereas $G$ remains nearly constant for all SMI variations. The constant $G$ value across SMI variations can be explained by an increase of both thermal capacity and conductivity with increasing SMI leading to an almost constant thermal diffusivity. The $10 \%$ solar irradiance reduction decreases the magnitude of LE, $H$, and $G$. As shown in Figs. $7 b-d$, LE decreases by $5 \%$, independent of SMI and soil type variation. To the contrary, $H$ decreases more and $G$ decreases less with an increasing SMI. We note that these variations in SEB partitioning with increasing SMI are amplified with increasing clay percentage in the soil, a feature that likely results from the role that soil quartz content plays in determining thermal conductivity and diffusivity: that is, higher quartz content reduces the ability for variations in thermal conductivity and heat capacity to balance each other with increasing SMI.

This offline-LSM investigation of the EF response to variations in SMI and soil type suggests that the aforementioned 2\%-3\% cloud-induced increase in EF is not a function of either SMI or soil type (ranging from pure loam to pure clay).

\section{b. Local surface response}

Shallow clouds passing over a fixed point at the surface induces rapid changes in $Q$, which leads to an imbalance between the atmosphere and the surface from which the surface must recover. Figure 8 shows a 1-h time evolution of the instantaneous SEB terms (sampled every $50 \mathrm{~s}$ ) at a single surface grid point (Fig. 8a) and of the SEB terms relative to the $Q$ (Fig. 8b). Clouds suddenly decrease the net radiation from 800 to $200 \mathrm{~W} \mathrm{~m}^{-2}$. The surface responds immediately by rapidly dropping $H$ and LE down from about 220 and $400 \mathrm{~W} \mathrm{~m}^{-2}$ to about 50 and $200 \mathrm{~W} \mathrm{~m}^{-2}$, respectively (Fig. 8a). As previously discussed, with respect to the horizontally averaged results, the sensible heat flux decreases proportionally with the net radiation (i.e., the normalized sensible heat flux remains equal to about $0.3 Q$ when shallow clouds pass over head; Fig. 8 b). Therefore, $H$ reacts similarly whether considering the average or the local immediate response. Contrary to this finding for $H, \mathrm{LE}$ is about $0.5 Q$ in the unshaded areas and increases to about $1.3 Q$ under the cloud. So, the latent heat flux density from the 

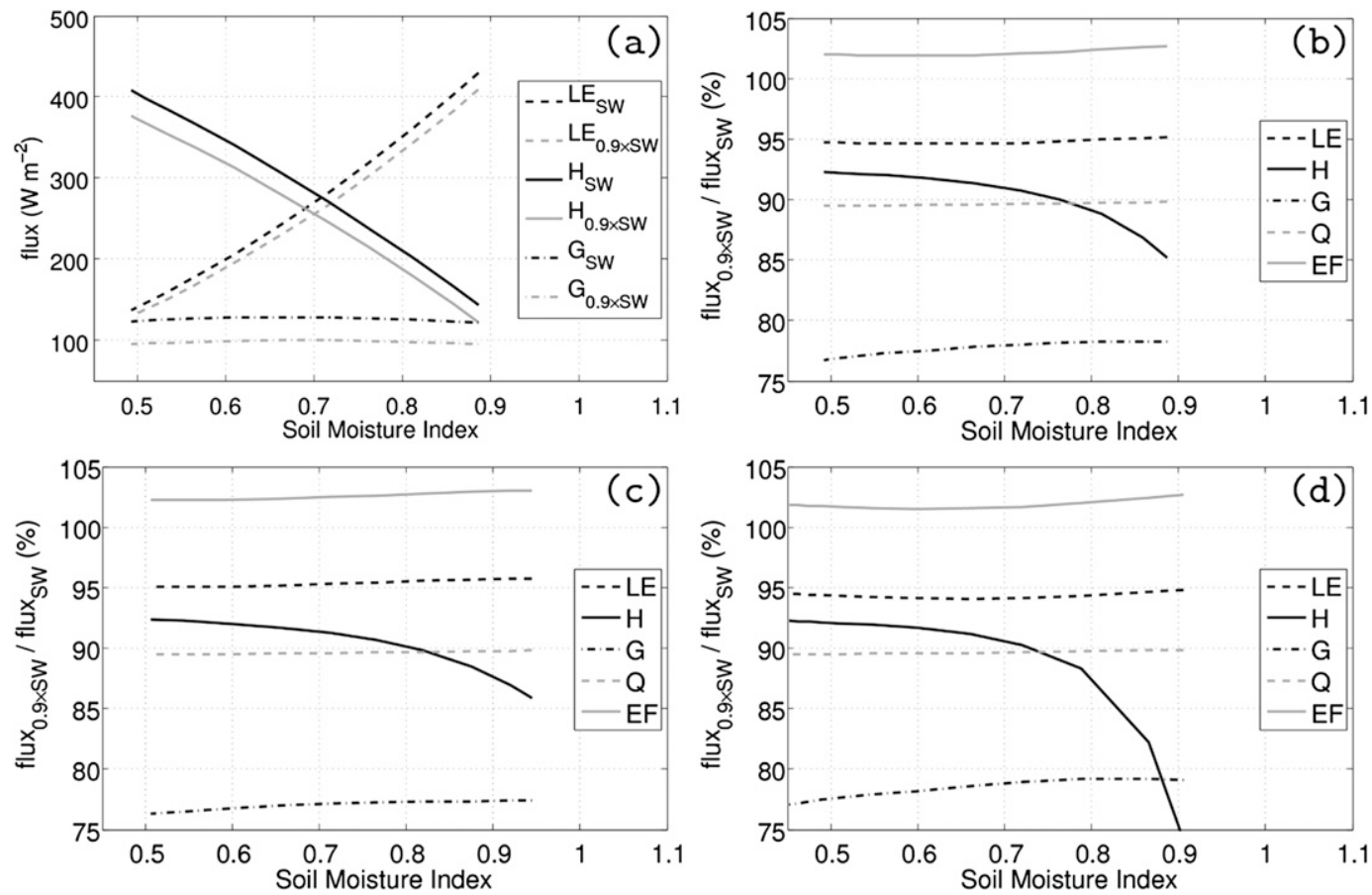

FIG. 7. (a) Variations of LE, $H$, and $G$ against soil moisture index for the clay-loam soil type from the offline onedimensional LSM simulations. The gray lines depict results when reducing the solar irradiance (SW) by $10 \%$ compared to the irradiance used for the dark line. The subsequent three panels present the SEB terms and EF for a $10 \%$ solar irradiance reduction relative to their respective values without reducing the solar irradiance against SMI for three soil types: (b) clay-loam, (c) loam, and (d) clay.

shaded surface is higher than the surface net radiative flux density. The soil heat flux compensates this imbalance shifting from $150 \mathrm{~W} \mathrm{~m}^{-2}$ (or $\sim 0.2 Q$ ) in the unshaded area down to $-100 \mathrm{Wm}^{-2}(\sim-0.5 Q)$ when clouds are overhead (Fig. 8). Therefore, the available energy reduction during a cloud's passage results in heat stored in the soil diffusing toward the surface and largely being consumed by evaporation.

The large soil heat flux variations illuminate the key role the soil plays in determining the partitioning between sensible and latent heat flux under rapidly varying solar irradiance: $Q=\mathrm{LE}+H+G$, with $Q=$ $1.2 Q+0.3 Q-0.5 Q$ under the clouds and $Q=0.5 Q+$ $0.3 Q+0.2 Q$ in the unshaded areas. From these results one can deduce that EF varies greatly over the surface, increasing from 0.6 in unshaded areas to 0.8 under the clouds. While EF slightly increases in average at regional scale $(2 \%-3 \%)$ as seen in Fig. 6, local EF variations are substantially larger (30\%).

The $G$ variations result from immediate and large skin temperature response to overpassing clouds (Fig. 8c). The $4^{\circ} \mathrm{C}$-cooling response of skin temperature in response to the $1000-200 \mathrm{~W} \mathrm{~m}^{2}$ solar irradiance decrease is slightly lower than what is observed on 21 June at the ARM SGP site where a $6^{\circ} \mathrm{C}$ cooling for a solar irradiance decrease from 1000 to $400 \mathrm{~W} \mathrm{~m}^{2}$ was observed. This large skin temperature variation in response to rapid radiative forcing variations has been previously discussed in Gentine et al. (2011b). Slow diffusion of heat in the ground leads to highly variable skin temperature, whereas deeper soil maintains nearly constant temperature for high-frequency radiative forcing variations. As a result, the soil heat flux immediately responds, in phase, to rapid irradiance variations, which is not the case when low-frequency radiative forcings are considered. Gentine et al. (2011b) pointed out that, because heat propagates efficiently in the atmosphere, nearsurface air temperature does not respond to rapid radiative surface forcing variations. Consistent with Gentine et al.'s (2011b) findings, Fig. 8c reveals that both the cloudy boundary simulated here and the ARM measurements reveal nearly constant near-surface air temperature in response to solar irradiance variations.

These results offer insight on the impact of shallow cumulus clouds when diagnosing $G$ as an empirical fraction of $Q$ (e.g., Kustas and Daughtry 1990; Santanello and Friedl 2003; Bateni and Entekhabi 2012). These results are also important because of the difficulties in observing soil heat flux experimentally, even for cloud-free PBLs (e.g., Small and Kurc 2003), and they confirm the 

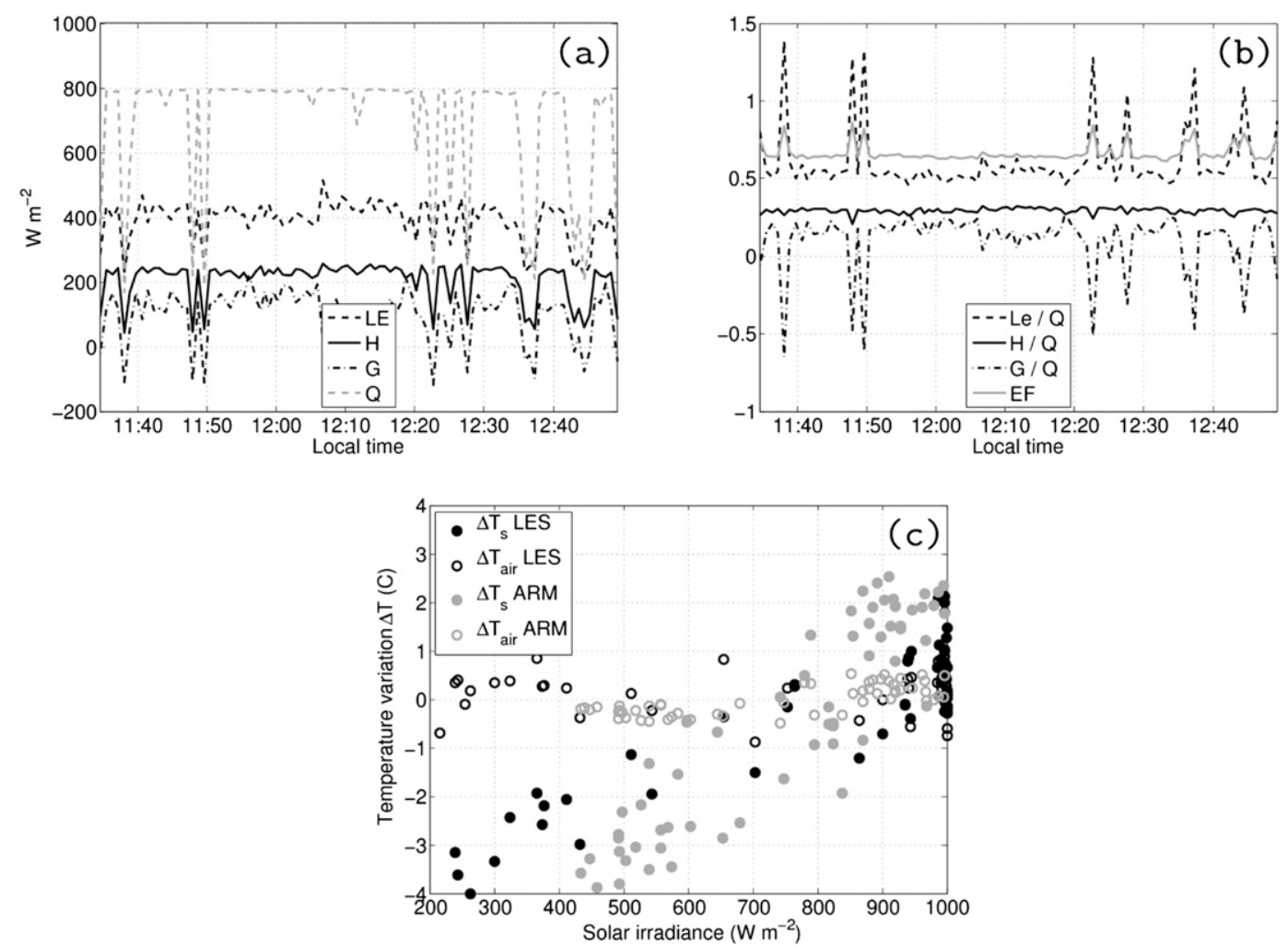

FIG. 8. (a) The 1-h time evolution of the SEB terms at a single grid point during the passage of shallow cumulus clouds. (b) As in (a), except $H, \mathrm{LE}$, and $G$ are normalized by the local net radiation $Q$. Local variation of EF is superposed. (c) Air and skin temperature anomalies $\Delta T_{\text {air }}$ and $\Delta T_{s}$, respectively, from the mean value according the solar irradiance. Black dots are for the simulated values during the 1-h period already presented in (a) and (b) and gray dots are for measurements acquired at ARM SGP site between 1100 and 1200 LST 21 Jun.

difficulty to experimentally determine $H$, LE, and consequently EF in the presence of shallow cumuli. Current measurement strategies are not yet able to provide spatial measurements over a sufficiently large region of space at a single instant in time to allow observations of the ensemble mean (as is the case in LES run). Researchers typically measure at a single point for a long time period and utilize Taylor's frozen turbulence hypothesis to translate between time and space. The choice of the averaging duration is then a difficult compromise between a sufficient duration to obtain a robust statistics of all turbulent time scales and a short enough duration to allow application of Taylor's hypothesis. In cloudy boundary layers, this compromise is almost impossible where fluxes fluctuate substantially over time even within a 1-h sample.

\section{c. Impact of the LSM vertical resolution}

The dependence of the results on the depth of the first soil layer is now considered. The offline onedimensional Noah LSM is used with three different vertical resolutions, where the layer's bottom limits are
1) $[0.1,0.2,0.6,1] \mathrm{m} ; 2)[0.05,0.2,0.6,1] \mathrm{m}$ (the resolution used in the 3D LES); and 3) $[0.01,0.2,0.6,1] \mathrm{m}$. The sensitivity tests are performed in a similar way to those described in section 2, where cloud passages are simulated by different solar irradiance reductions $\left(\mathrm{SW}_{\text {shaded }}\right)$, ranging from 0.9 (for shallow cumulus) to 0.3 (for deeper cumulus) times the solar irradiance in the unshaded area ( $\left.\mathrm{SW}_{\text {unshaded }}\right)$. Figure 9 shows the variation of the SEB terms normalized by $Q$ immediately following the solar irradiance reduction against the imposed reduction $\left(\mathrm{SW}_{\text {shaded }} / \mathrm{SW}_{\text {unshaded }}\right)$. The $Q$ value in the shaded area used in normalizing the SEB terms is also indicated. When the solar irradiance remains near to its maximum value (i.e., shallow clouds: $\mathrm{SW}_{\text {shaded }} / \mathrm{SW}_{\text {unshaded }}=0.9$ or $Q=600 \mathrm{~W} \mathrm{~m}^{2}$ ), all three different vertical soil resolutions produce similar results which are close to the LESderived SEB components for the unshaded area (Fig. 8b), with $G=0.2 Q, H=0.3 Q$, and $\mathrm{LE}=0.5 Q$. The more the reduction increases (i.e., for deeper clouds: $\mathrm{SW}_{\text {shaded }} /$ $\mathrm{SW}_{\text {unshaded }}=0.3$ or $Q=200 \mathrm{~W} \mathrm{~m}^{2}$ ), the results diverge, emphasizing that the SEB partition is vertical-resolution dependent. A deep upper soil layer $(0.1 \mathrm{~m})$ prevents 


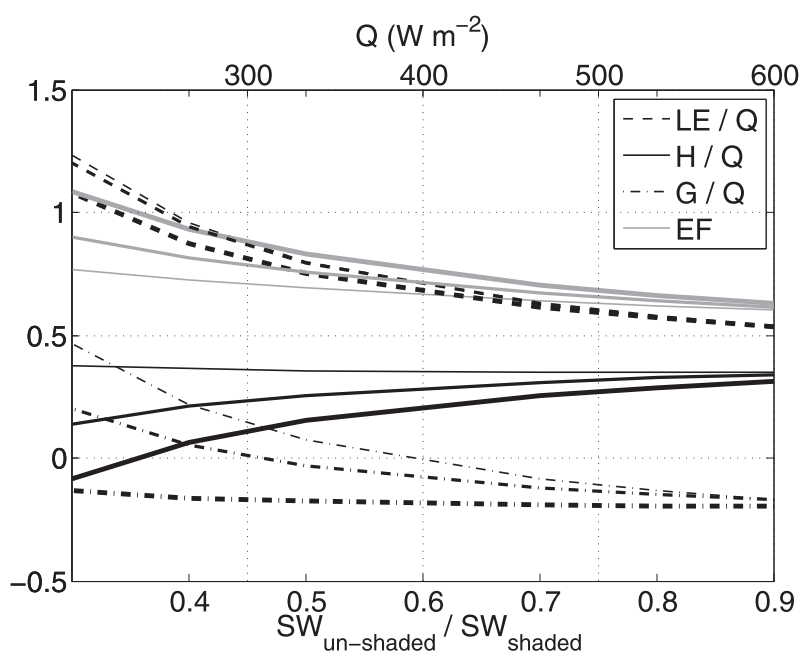

FIG. 9. SEB terms (LE, $H$, and $G$ ), normalized by $Q$ in shaded area against the solar irradiance reduction $\left(\mathrm{SW}_{\text {shaded }} / \mathrm{SW}_{\text {unshaded }}\right)$ on lower $x$ axis and $Q$ in the shaded area on upper $x$ axis. The thin, medium, and thick lines represent the three vertical soil resolutions used in the sensitivity test, where the bottom limit of each layer is at $[0.01,0.2,0.6,1],[0.05,0.2,0.6,1]$, and $[0.1,0.2,0.6,1] \mathrm{m}$.

thermal diffusion toward the surface to compensate skin temperature decrease. The upper layer is then too deep and the shading too abrupt for the slow process of thermal diffusion. Therefore, $G / Q$ remains constant no matter the magnitude of the solar irradiance reduction and $H / Q$ strongly decreases with cloud deepening (even reverses sign for very deep clouds). A thinner upper layer allows thermal diffusion, leading to $G$ 's sign reversal under deep clouds and therefore to a constant value of $H / Q$. On the contrary, LE/Q has almost the same evolution whatever the depth of the upper layer. To conclude, for rapid solar irradiance changes like that for shallow clouds, the use of 0.1-m-deep upper layer is inadequate since it does not allow sufficient thermal diffusion in the ground. The 0.05- and 0.01-m-deep upper layers give similar trends, but with slightly different amplitudes.

\section{Radiative and atmospheric turbulence impact on surface energy balance}

In Noah, bare-soil evaporation is parameterized as a fraction of the potential evaporation: $\mathrm{LE}=\mathrm{SMI} \times E_{p}$, where the potential evaporation $E_{p}$ is estimated using the Penman equation (Penman 1948; Monteith 1981),

$$
E_{p}=\frac{\Delta Q+\rho C_{p} \delta q r_{a}^{-1}}{\Delta+\left(C_{p} / L_{v}\right)\left(1+r_{s} / r_{a}\right)},
$$

where $\Delta\left(\mathrm{kg} \mathrm{kg}^{-1} \mathrm{~K}^{-1}\right)$ is the slope of the saturated specific humidity curve against temperature; $\rho\left(\mathrm{kg} \mathrm{m}^{-3}\right)$ is the air density; $C_{p}\left(\mathrm{~J} \mathrm{~kg}^{-1} \mathrm{~K}^{-1}\right)$ is the heat capacity of air at constant pressure; $\delta q\left(\mathrm{~kg} \mathrm{~kg}^{-1}\right)$ is the specific humidity deficit; $r_{a}$ and $r_{s}\left(\mathrm{~s} \mathrm{~m}^{-1}\right)$ are the atmospheric and surface resistances, respectively; and $L_{v}\left(\mathrm{~J} \mathrm{~kg}^{-1}\right)$ is the latent heat of vaporization.

The first term in the numerator of Eq. (4) (i.e., $\Delta Q$ ) is proportional to the atmospheric radiative forcing. The second term takes into account both the atmospheric thermodynamical forcing (through $\delta q$ ) and the dynamical forcing [through $r_{a}$, where $r_{a}=\left(U C_{h}\right)^{-1}$, with $U$ representing the local horizontal wind speed and $C_{h}$ representing the atmospheric exchange coefficient, which is a function of stability]. Intermittent passage of clouds overhead ensures that the radiative and atmospheric controls on $E_{p}$ vary spatially across the LES domain; their effects on the SEB are now investigated (Fig. 1, point II).

Figure 10a shows a strong correlation $(>0.9)$ between the local variations in latent heat flux and solar irradiance, confirming that $\Delta Q$ in Eq. (4) most strongly controls $E_{p}$ variability in cloudy boundary layers. However, if $E_{p}$ were solely controlled by $\Delta Q$, this correlation would be 1 . The LE scatter about the linear trend between flux and solar irradiance (Fig. 10a) results from the turbulence and the cloud-induced turbulence and secondary circulations, which modify local winds, stability, and consequently surface fluxes. This link between the surface flux variations and cloud activity is now analyzed.

After removing the variation of LE with $Q$ by detrending, Fig. 10b presents the spatial standard deviation of the sensible and latent heat fluxes [defined as $\sigma_{\text {Flux }}=$ $\left\langle\left(\text { Flux }-\langle\text { Flux }\rangle_{A}\right)^{2}\right\rangle_{A}^{1 / 2}$, where $A$ implies a horizontal average over either the shaded or unshaded areas] normalized by each respective surface flux horizontally averaged over the entire domain plotted against cloud activity (characterized by the LWP) for every time step between 1000 and 1300 LST. It is important to note that normalization by the instantaneous horizontally averaged surface flux at each time step eliminates any diurnal variation.

Generally, increasing cloud activity (i.e., increasing LWP) generates slight $(\sim 7 \%-10 \%)$ increases in the variability of the surface fluxes over both shaded and unshaded areas (Fig. 10b), with $\sigma_{H_{S}} /\langle H\rangle$ being the exception, showing no increase. Variability of the atmospheric surface exchange coefficient also increases with increasing LWP (Fig. 10c), ${ }^{1}$ but $\sigma_{C_{h}} /\left\langle C_{h}\right\rangle$ increases substantially under the clouds (i.e., by about $25 \%$ in the shaded area). Therefore, cloud-induced turbulence and/ or secondary circulations act to generally increase

\footnotetext{
${ }^{1}$ Recall that $H$ and LE both use the same locally determined surface exchange coefficient $C_{h}$.
} 

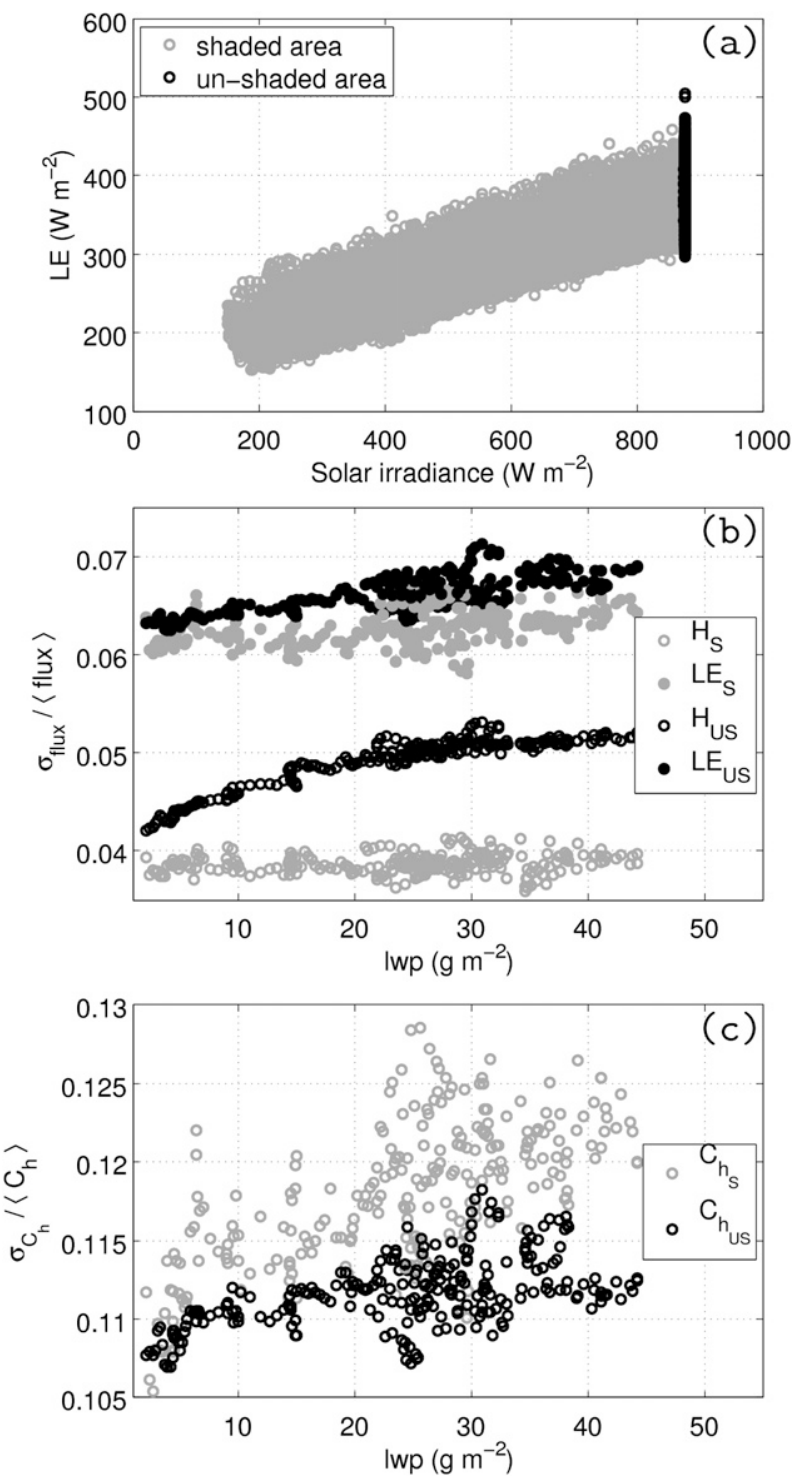

FIG. 10. (a) LE against solar irradiance at each surface grid point at 1100 LST. The gray and black circles are for each grid point in the shaded and unshaded areas, respectively. (b) Standard deviation of $H$ and LE over shaded (subscript $s$ ) and unshaded area (subscript us), normalized by the surface flux (horizontally averaged over the entire domain) against LWP during the simulation. In the shaded areas, $H$ and $\mathrm{LE}$ are first detrended to remove the influence of radiation. (c) As in (b), but for the atmospheric scalar exchange coefficient $C_{h}$.

subcloud exchange coefficient variability, which increases surface flux variability. Although this cloudinduced variability is minor compared to the mean flux reduction resulting from the clouds' radiative impact, the variability may be sufficient to participate in initiating additional clouds and/or triggering convection.

These results partly explain why LE reduces by only $5 \%$ in response to a $10 \%$ solar irradiance reduction (irrespective of soil moisture and type), while $H$ and $G$ exhibit a distinct response to soil moisture and type variations (as seen in section 3; Fig. 7). It appears that, for cloudy boundary layers, the atmospheric forcing represented by the second term in the numerator of Eq. (4) does not affect LE on average. Therefore, reduction of domain-averaged LE results largely from the reduction in the radiative forcing term, while $H$ is directly linked to the skin temperature, whose value depends on $G$ and therefore on the soil type and soil moisture.

\section{Boundary layer response to cloud-induced surface flux heterogeneity}

\section{a. Vertical buoyancy flux}

The atmospheric response to the cloud-induced surface flux heterogeneity (Fig. 1, point III) is now investigated. Although this topic can be considered from a variety of viewpoints, this section will focus on the vertical buoyancy flux.

In the subcloud layer, cloud roots are associated with well-defined strong updrafts of warmer/moister air than in the surroundings (Lohou et al. 1998). An example cloud root from the simulation is presented in Fig. 11 with instantaneous $y-z$ slices of $w, \theta$, and $r_{v}$ at 1300 LST. The spatial variation of net radiation is included in the figure to identify the areas shaded by cloud. Figure 12 presents the total vertical turbulent transport of heat and moisture (i.e., the sum of the resolved and subfilterscale contributions to the flux).

Contrary to the mean parameters (Fig. 11), instantaneous slices of total vertical flux (Fig. 12) do not clearly reveal the cloud root. In fact, without the overlaid surface fluxes, one would have difficulty locating the cloud root within the slices of local heat and moisture vertical transport. However, from the surface up to $200 \mathrm{~m}$, regions of larger magnitude local heat and moisture fluxes can be seen (sometimes at both edges of the shaded areas, sometimes at just one edge). Therefore, the definition of a cloud root in the context of local heat and moisture fluxes remains unclear.

To further generalize this result, Fig. 13 presents vertical slices of the simulation's average cloud root. As mentioned in section 2, the sun in this simulation is always directly overhead (i.e., at the zenith position). Therefore, in this study, the cloud root is defined as the air column directly above the shaded area. Using instantaneous vertical slices oriented both along and transverse to the geostrophic wind, average cloud roots were created by 1) selecting regions within each slice matching the criteria that the cloud shading spans at least $1 \mathrm{~km}$ in the horizontal direction (i.e., only larger 

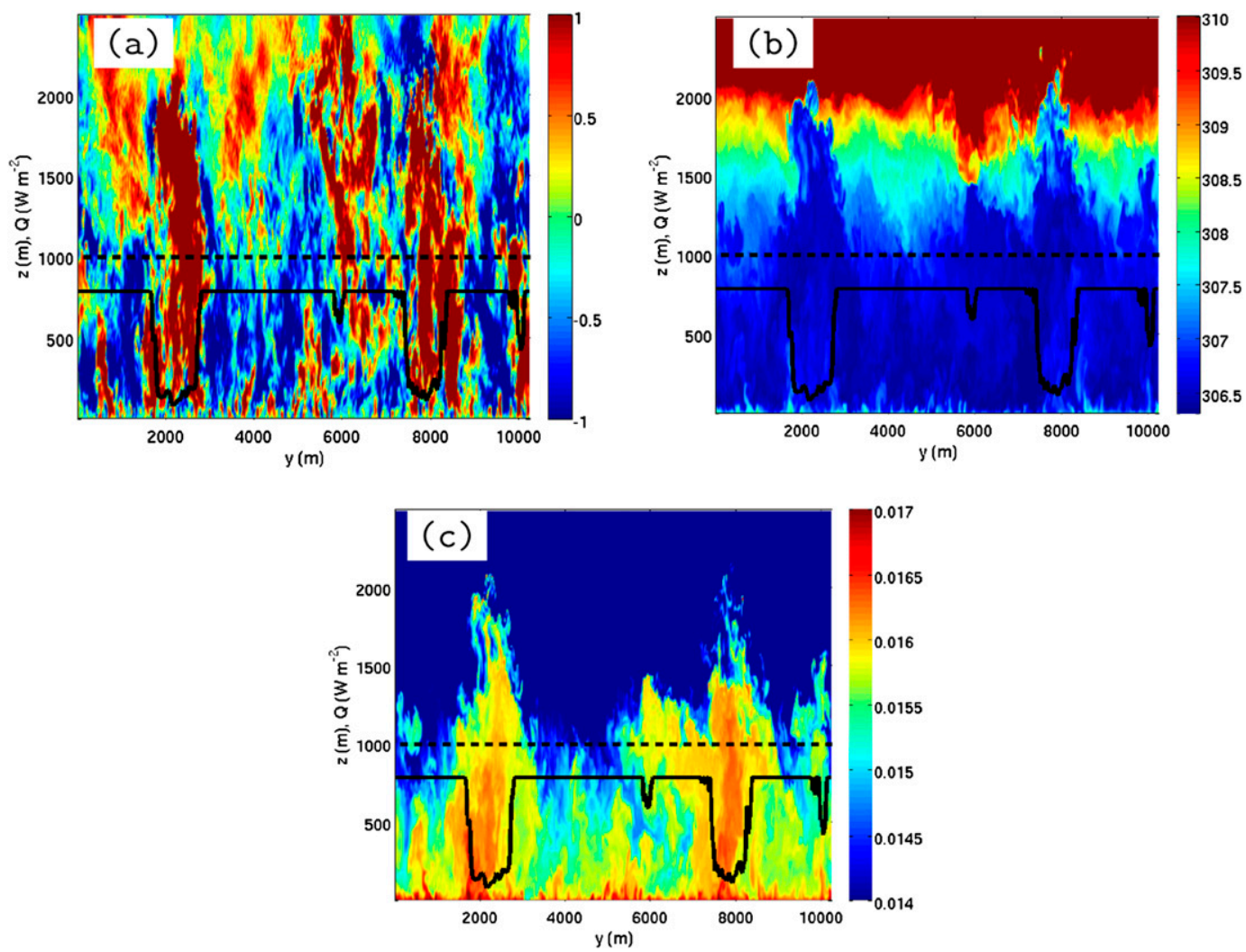

FIG. 11. An instantaneous south-north vertical slice of (a) vertical velocity $w\left(\mathrm{~m} \mathrm{~s}^{-1}\right)$, (b) $\theta(\mathrm{K})$, and (c) $r_{v}\left(\mathrm{~kg} \mathrm{~kg}^{-1}\right)$ at 1300 LST (shaded). The horizontal dashed black line indicates the horizontally averaged subcloud-layer height $\left\langle z_{\mathrm{sl}}\right\rangle$ and the solid black line depicts the local net radiative forcing $Q$ for this slice.

clouds), 2) scaling each sample spatially to a standard length $L, 3$ ) shifting the centroid of that scaled sample to a virtual origin $(x / L=0$ and $y / L=0)$, and 4$)$ averaging each of these events occurring between 1230 and 1330 LST. The vertical slices presented in Fig. 13 therefore involve an average of more than 100 individual cloud-root samples, and the shaded area lies in the ranges $-0.5<x / L<+0.5$ and $-0.5<y / L<+0.5$.

Very close to the ground, vertical slices aligned both along and transverse to the mean westerly wind (Fig. 13) confirm reduced vertical heat and moisture transport over the shaded area, which is in agreement with the
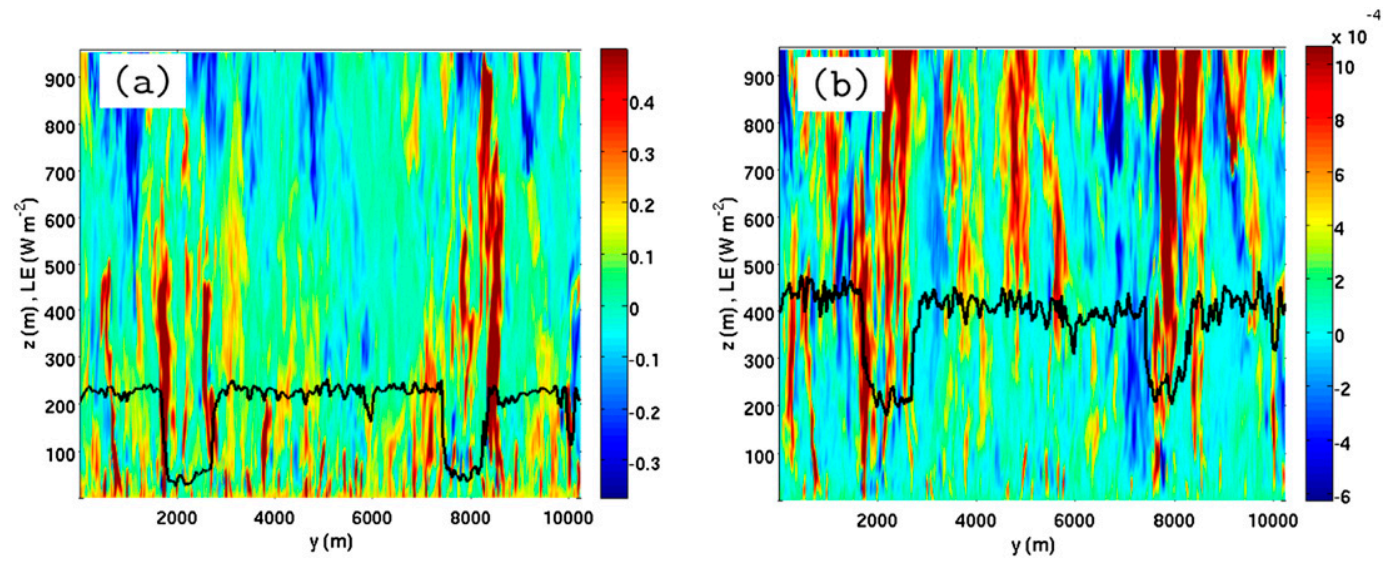

FIG. 12. As in Fig. 11, but for instantaneous slices of (a) $w^{\prime} \theta^{\prime}\left(\mathrm{m} \mathrm{s}^{-1} \mathrm{~K}\right)$ and (b) $w^{\prime} r_{v}^{\prime}\left(\mathrm{m} \mathrm{s}^{-1} \mathrm{~kg} \mathrm{~kg}^{-1}\right)$ through the subcloud layer. The black lines indicate (a) $H$ and (b) LE along the vertical slice $\left(\mathrm{W} \mathrm{m}^{-2}\right)$. 

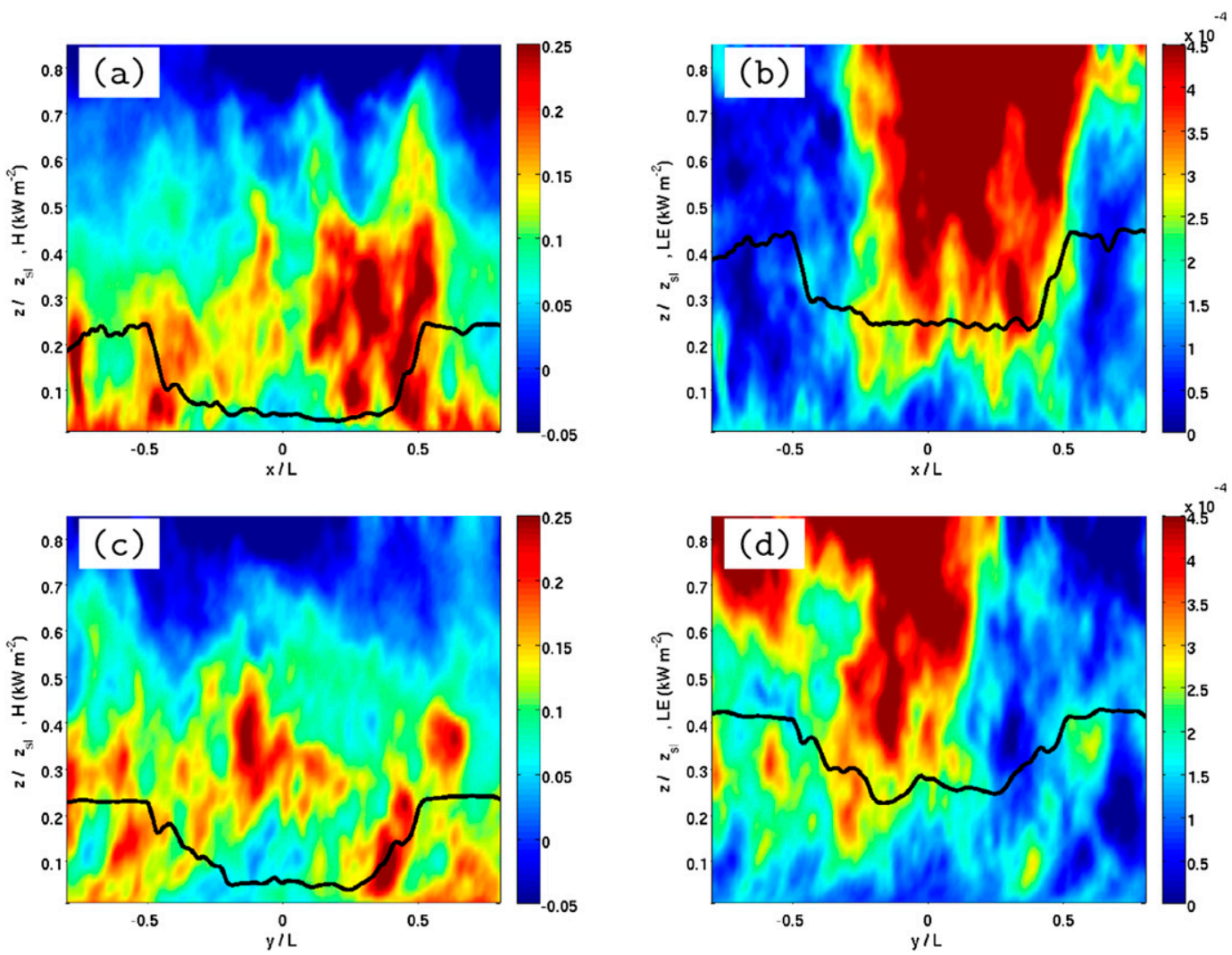

FIG. 13. Averaged vertical slice of (a),(c) $w^{\prime} \theta^{\prime}\left(\mathrm{m} \mathrm{s}^{-1} \mathrm{~K}\right)$ and (b), (d) $w^{\prime} r_{v}^{\prime}\left(\mathrm{kg} \mathrm{kg}^{-1}\right)$ in the cloud root, where (a) and (b) show the variables in the plane parallel to the geostrophic wind and (c) and (d) show the same variables in the plane transverse to the geostrophic wind. The average shading is in the range $-0.5<x / L<+0.5$ and $-0.5<y / L<+0.5$, where $L$ is the shaded area width along the slice. The black lines laid over top indicate the average surface (left) $H$ and (right) LE.

underlying surface fluxes. Above the surface (from the ground to $0.2 z_{\mathrm{sl}}$ ), atmospheric heat and moisture fluxes clearly reveal the surface heterogeneity's effect (Fig. 13). High-magnitude heat and moisture vertical transport at the shaded area's edges (in the lowest $200 \mathrm{~m}$ ) suggests enhanced vertical transport between the warm and relatively cold surfaces surrounding the shaded region, with this high buoyancy flux merging into a cloud root above $200 \mathrm{~m}$.

Several numerical studies already showed that buoyant convection over heterogeneous surfaces occurs at the upwind edge of the warm patch (e.g., Raasch and Harbusch 2001; Patton et al. 2005; Courault et al. 2007). However, the size of the surface heterogeneity in those studies was much larger than the cloud-induced shading under investigation here. It is also important to point out that those investigations also studied breeze circulations driven by horizontal temperature and soil moisture gradients (Taylor et al. 2012), while in our case the dynamical circulation between shaded and unshaded areas might be linked to the cloud-induced convection tending to generate convergence into the cloud root.
The mean wind's effect is noticeable under the cloud base in Figs. 13a and 13b. The core with the upward transport of moisture under the cloud base is not centered but shifted downwind in the range $0<x / L<+0.5$. On the contrary, the core of upward transport is notably centered in the transverse vertical slices (Figs. 13c,d).

To elaborate more fully on the influence of clouds on vertical transport, Fig. 14 presents the contribution to the total vertical flux $F_{T}$ from shaded areas $F_{s}$ versus unshaded areas $F_{\text {us }}$, where $F$ can be either $H$ or LE. The profiles in Fig. 14 are averaged over the same 3D volumes used to create Fig. 13.

If $S_{s}$ and $S_{\text {us }}$ describe the shaded and unshaded areas of the total surface area $S_{T}$, the fluxes $F_{s}, F_{\text {us }}$, and $F_{T}$ are linked by

$$
F_{T}=\frac{S_{s}}{S_{T}} F_{s}+\frac{S_{\mathrm{us}}}{S_{T}} F_{\mathrm{us}}
$$

The cloud-induced surface flux heterogeneity reduces the buoyancy flux from the surface up to $0.2\left\langle z_{\mathrm{si}}\right\rangle$ over shaded areas (Fig. 14), where, for example, the buoyancy 

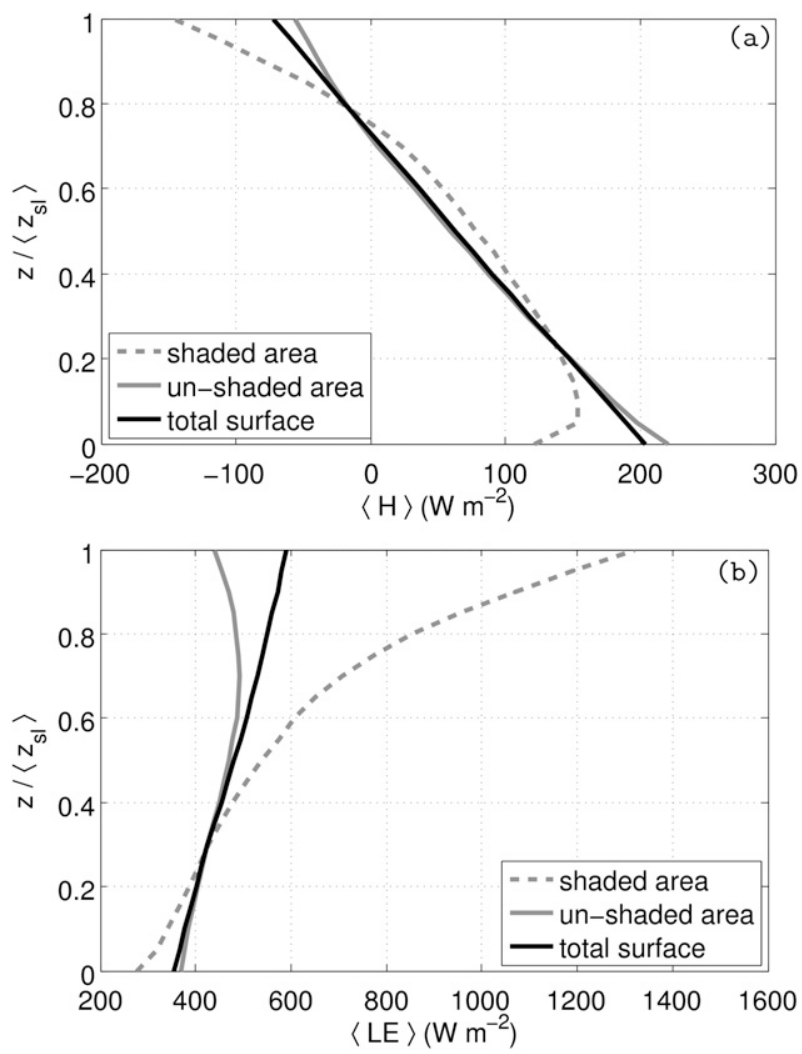

FIG. 14. Horizontal- and 1-h-averaged (a) $H$ and (b) LE against normalized height $z /\left\langle z_{\mathrm{sl}}\right\rangle$. The solid black line depicts the total flux and the gray lines depict the contribution to that total flux occurring in the shaded (dashed) and unshaded (solid) areas.

flux at $0.1\left\langle z_{\mathrm{sl}}\right\rangle$ is reduced by $15 \%$. In the range $0.2<$ $z /\left\langle z_{\mathrm{sl}}\right\rangle<0.8$, the cloud root exhibits stronger buoyancy flux than the surroundings, whereas above $0.8\left\langle z_{\mathrm{sl}}\right\rangle$ latent and sensible heat flux reveal the opposite behavior (with a strong increase of latent heat flux and a slight decrease of sensible heat flux with height). Figure $14 \mathrm{~b}$ points out that the drying of the boundary layer within the cloud $\operatorname{root}\left(1300 \mathrm{~W} \mathrm{~m}^{-2}\right.$, with $w^{\prime}>0$ and $\left.q^{\prime}>0\right)$ is 3 times the drying occurring by entrainment of dry tropospheric air into the boundary layer external to the cloud $\left(440 \mathrm{~W} \mathrm{~m}^{-2}\right.$, with $w^{\prime}<0$ and $q^{\prime}<0$ ).

\section{b. Entrainment}

Entrainment at the boundary layer's upper interface with the free troposphere contributes to heating and drying in the boundary layer and tends to increase the surface evaporation (Heerwaarden et al. 2009). Beyond modifying the mean thermodynamical boundary layer characteristics, the downward dry and warm tongues coming from the PBL top can be detected in the surface layer (Lohou et al. 2010) on the turbulent time scales of temperature and moisture.
In the dry boundary layer, the entrainment rate is typically quantified by $A$, which is defined as the ratio of minus the buoyancy flux at the boundary layer top relative to the surface buoyancy flux (e.g., Deardorff et al. 1980; Sullivan et al. 1998). The formulation of $A$ is derived directly from the horizontally homogeneous buoyancy flux equation, making a variety of assumptions. As such, entrainment rates also depend on conditions at boundary layer top, such as the inversion strength and wind shear (e.g., Sullivan et al. 1998; Pino et al. 2003; Conzemius and Fedorovich 2006; Canut et al. 2010). From laboratory experiments, $A$ is approximately 0.25 (e.g., Deardorff et al. 1980), although significant controversy remains regarding the value of $A$ (e.g., Fernando 1991). The large variation of proposed values for $A$ results partly from the method used to estimate the buoyancy flux at the boundary layer top, typically using linear extrapolation of the buoyancy flux profile up to the boundary layer top, but can also be attributed to the dependence of $A$ on the Reynolds, Prandtl, and Peclet numbers of the fluid under consideration (e.g., Jonker et al. 2012).

Figure 14 reveals modifications to the upper portion of the mean vertical flux profiles in the shaded and unshaded areas, which suggests that clouds modify the PBL-top buoyancy flux partitioning and potentially the entrainment rate (Fig. 1, point IV). Figure 15 presents the temporal evolution of $A$ and its breakdown between sensible $\left(A_{\theta}\right)$ and latent $\left(A_{r_{v}}\right)$ heat contributions at $\left\langle z_{\mathrm{sl}}\right\rangle$ over the simulation's duration, where the breakdown can be written approximately as

$$
A \approx A_{\theta}+A_{r_{v}},
$$

where $A_{\theta}=-\left(1+0.61\left\langle r_{v}\right\rangle\right)\left(\left\langle w^{\prime} \theta^{\prime}\right\rangle_{z_{\mathrm{s}}} /\left\langle w^{\prime} \theta_{v}^{\prime}\right\rangle_{z_{0}}\right), \quad A_{r_{v}}=$ $-0.61\langle\theta\rangle\left(\left\langle w^{\prime} r_{v}^{\prime}\right\rangle_{z_{\mathrm{s}}} /\left\langle w^{\prime} \theta_{v}^{\prime}\right\rangle_{z_{0}}\right)$, subscript $z_{0}$ refers to the surface, and subscript $z_{\mathrm{sl}}$ was defined above; note that $A_{\theta}$ and $A_{r_{v}}$ are defined relative to the total surface buoyancy flux $\left\langle w^{\prime} \theta_{v}^{\prime}\right\rangle_{z_{0}}$. As presented in Fig. 15a, $A$ is calculated directly from the total buoyancy flux profile [without presuming the validity of Eq. (6)]; the "almost equal to" symbol in Eq. (6) results from neglecting the third-order term (proportional to $\left\langle w^{\prime} \theta_{v}^{\prime} r_{v}^{\prime}\right\rangle$ ) that should appear in the equation. Comparing $A$ calculated directly from the total buoyancy flux profile (shown in Fig. 15a) with $A$ calculated using Eq. (6) (not shown) reveals that the third-order term is sufficiently small to be neglected. In Fig. 15a, the liquid water path evolution indicates the cloud layer's development.

The temporal evolution of $A_{\theta}$ and $A_{r_{v}}$ is obviously connected to the cloud activity at both diurnal and shorter time scales. One can discern from Fig. 15a that $A_{\theta}$ imposes smaller-scale changes on $A$, while $A_{r_{v}}$ is 

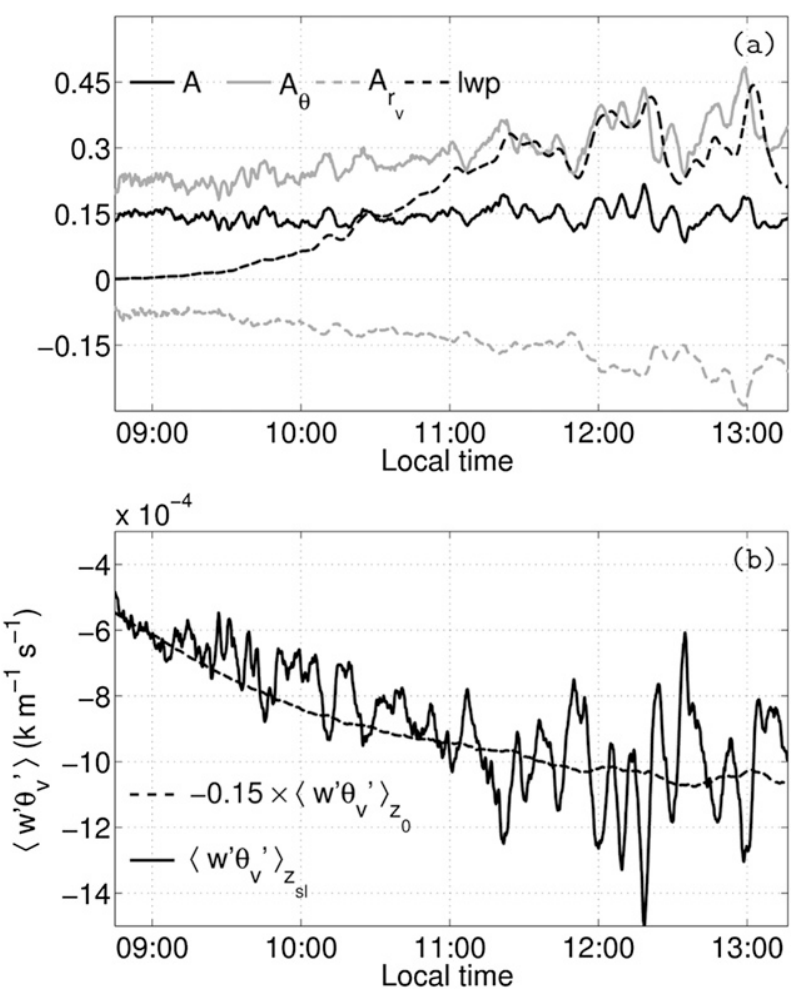

FIG. 15. (a) Temporal evolution of the entrainment rate $A$ and its sensible $\left(A_{\theta}\right)$ and latent $\left(A_{r_{v}}\right)$ contributions. The LWP $\left(\mathrm{hg} \mathrm{m}^{-2}\right)$ is also included to show cloud activity. (b) Temporal evolution of surface buoyancy flux $\left(\left\langle w^{\prime} \theta_{v}^{\prime}\right\rangle_{z_{0}}\right)$ times the mean entrainment rate and of the buoyancy flux at subcloud-layer top $\left\langle w^{\prime} \theta_{v}^{\prime}\right\rangle_{z_{\text {sl }}}$.

notably smoother and generally follows the cloud activity development. In agreement with Fig. 14, Fig. 15a reveals that, during times of greater cloud activity, the horizontally averaged latent heat flux profile tends to decrease its positive slope and the horizontally averaged sensible heat flux profile tends to decrease its negative slope. However, the buoyancy forcing increase from increasing latent heat flux below cloud base is generally compensated by a decrease of buoyancy forcing via decreasing sensible heat flux, leading to a generally constant $A$ of around 0.15 along the simulation; this finding is consistent with and confirms Nicholls and LeMone's (1980) result obtained using aircraft data during the Global Atmospheric Research Program (GARP) Atlantic Tropical Experiment (GATE) experiment. However, Fig. 15a reveals that $A$ oscillates between 0.1 and 0.2 , suggesting that the competing sensible and latent contributions do not completely compensate at short time scales. The increase of $A$ with cloud activity could result from both 1) a reduction of surface buoyancy flux in response to solar irradiance reduction and/ or 2) an increased buoyancy flux at subcloud-layer top $\left(\left\langle w^{\prime} \theta_{v}^{\prime}\right\rangle_{z_{\mathrm{sl}}}\right)$. Figure $15 \mathrm{~b}$ shows the different responses of these two fluxes. Horizontally averaged surface buoyancy flux has a very smoothed and low-amplitude response, which is perfectly in phase with the net radiation reduction as seen in Fig. 6, whereas the horizontally averaged buoyancy flux at the subcloud-layer top reveals a higher-frequency and larger-amplitude response, in phase with cloud activity (LWP). While both $\left\langle w^{\prime} \theta_{v}^{\prime}\right\rangle_{z_{0}}$ and $\left\langle w^{\prime} \theta_{v}^{\prime}\right\rangle_{z_{\mathrm{sl}}}$ variations contribute to increased $A$ with increased cloud activity and then with solar irradiance reduction, $\left\langle w^{\prime} \theta_{v}^{\prime}\right\rangle_{z_{\text {sl }}}$ obviously reveals the dominant response to solar irradiance reduction.

\section{Discussion and conclusions}

Shallow cumuli represent a large portion of the cloud cover over land; however, their interaction with the surface energy balance (SEB) is poorly understood. One explanation for this lack of understanding lies in the difficulty to experimentally obtain estimates of the terms comprising the SEB terms. In this study, a large-eddy simulation code is coupled with a land surface model to investigate the coupling between the surface and the atmosphere in the presence of shallow cumuli.

From a regional perspective, shallow cumuli are found to generate a $2 \%-3 \%$ increase in evaporative fraction, no matter the soil type (ranging from pure loam to pure clay) or soil moisture regime, compared to EF for a similar surface without a cloud overhead. This increase in EF results from the nonlinear surface response to the cloud-induced reduction of the solar forcing: namely, cloud shading yields a lower decrease of the surface latent heat flux at regional scales $(5 \%)$ than the decrease of the surface sensible heat flux $(7 \%-15 \%)$. This limited reduction of the horizontally averaged LE largely results because evaporation locally increases to values higher than the available net radiation $Q$ in the areas shaded by clouds, which is compensated by a sign change in soil heat flux $G$. Therefore, when clouds pass overhead, heat moves toward the surface from deep in the soil and is consumed by evaporating surface water. The skin temperature decrease that leads to the sign change in ground heat flux also drives the sensible heat flux, which is always about one-third the local net radiation whether in or out of the shaded area. Therefore, in cloudy conditions, the skin temperature is a critical parameter in the surface energy balance, where skin temperature undergoes important local and abrupt variations of more than $4 \mathrm{~K}$.

As expected, the cloud-induced surface heterogeneities mainly result from the reduced solar forcing. The turbulence and secondary circulations associated with the cloud activity simply increase the flux variability at the surface. However, it would be interesting to investigate whether this variability can trigger cloud activity. 
An investigation into the impact of cloud-induced surface heterogeneities on the vertical transfer of heat and moisture reveals that the buoyancy flux is modified by cloud-induced surface flux heterogeneity up to about $0.2\left\langle z_{\mathrm{sl}}\right\rangle$. It is noteworthy that small-scale surface heterogeneities (with a horizontal scale of about $1 \mathrm{~km}$ ) lasting only a few minutes can impact vertical transfer to this height (i.e., above the surface layer). On the other hand, higher fluxes are not observed across all of the unshaded area but rather only near the edges of the shaded area. These high-buoyancy-flux regions progressively coalesce above $0.2\left\langle z_{\mathrm{sl}}\right\rangle$ to form the cloud's root. Cloud dynamics might become more important at this height, warranting future analysis.

Vertical sensible and latent heat flux profiles in the shaded and unshaded areas differ notably, especially above $0.8\left\langle z_{\mathrm{sl}}\right\rangle$, where the cloud root is defined by the atmospheric column above the shaded area. Between $0.8\left\langle z_{\mathrm{sl}}\right\rangle$ and the cloud base, the cloud root strongly contributes to drying and warming the boundary layer. These strong heat flux heterogeneities under the cloud base complicate airborne flux estimation by invalidating homogeneity and stationarity assumptions.

Despite sensible and latent flux modifications between the shaded and unshaded areas, the average buoyancy profile remains unchanged. The entrainment rate varies from 0.1 to 0.2 in response to cloud activity. Over the horizontal domain for long time scales, the cloud-induced latent heat flux increase to the buoyancy forcing determining the PBL's entrainment rate is largely compensated by a decrease in sensible heat flux. However, shallow cumuli activity increases the entrainment rate at shorter time scales.

As for any simulation of this kind, the imposed atmospheric and soil conditions largely determine the results. The case study presented is characterized by an important soil moisture index, coupled to a relatively warm boundary layer with high geostrophic wind. The impact of the soil moisture index on the SEB partitioning under reduced solar irradiance is analyzed in the offline results section and has been shown to be negligible. The ARM SGP 21 June case is characterized by a high-temperature regime, where boundary layer feedbacks on evapotranspiration are mainly driven by temperature variations (van Heerwaarden et al. 2010). For cooler regimes, we expect humidity variations to more largely affect boundary layer feedbacks controlling evapotranspiration than shown here; however, entrainment's influence on evapotranspiration is of second order compared to the sudden and large radiation forcing variations induced by clouds passing overhead. Finally, the clouds simulated here translate rapidly across the horizontal domain, a result from the $10 \mathrm{~m} \mathrm{~s}^{-1}$ geostrophic wind. This rapid horizontal translation of the cloud's shading on the surface may reduce the coupling between the cloud-induced surface heterogeneity and the atmosphere; as a consequence, the cloud-induced secondary circulations discussed here could be weaker than for cases with weaker winds.

Acknowledgments. The first author especially thanks Paul Sabatier University (Toulouse III, France) and the National Center for Atmospheric Research (NCAR) Advanced Study Program, Geophysical Turbulence Program, and MMM Division for supporting her visits to NCAR. The first author is indebted to NCAR's Boundary Layer and Turbulence group for making her stay a scientific and personal pleasure. Both authors are particularly grateful to Fei Chen, Dave Gochis, Harm Jonker, Peggy LeMone, Don Lenschow, Marie Lothon, Chin-Hoh Moeng, and Peter Sullivan for their fruitful discussions and to Anil Kumar for his help in using HRLDAS and the 1D LSM. Computer facilities were provided by Calcul en Midi-Pyrénées (CALMIP; France), NCAR, and the National Energy Research Scientific Computing Center (which is supported by the Office of Science of the U.S. Department of Energy under Contract DE-AC02-05CH11231). The second author's support came from a combination of 1) NCAR's Biohydro-atmosphere interactions of Energy, Aerosols, Carbon, $\mathrm{H}_{2} \mathrm{O}$, Organics \& Nitrogen (BEACHON) project and 2) the Center for Multiscale Modeling of Atmospheric Processes (CMMAP) at Colorado State University, NSF Grant ATM-0425247 and Contract G-3045-9 to NCAR.

\section{REFERENCES}

Bateni, S. M., and D. Entekhabi, 2012: Relative efficiency of land surface energy balance components. Water Resour. Res., 48 , W04510, doi:10.1029/2011WR011357.

Bellon, G., and B. Stevens, 2005: On bulk models of shallow cumulus convection. J. Atmos. Sci., 62, 3286-3302.

Betts, A. K., 2007: Coupling of water vapor convergence, clouds, precipitation, and land-surface processes. J. Geophys. Res., 112, D10108, doi:10.1029/2006JD008191.

- and W. Ridgway, 1988: Coupling of the radiative, convective, and surface fluxes over the equatorial Pacific. J. Atmos. Sci., 45, 522-536.

Bretherton, C. S., and S. Park, 2008: A new bulk shallow-cumulus model and implications for penetrative entrainment feedback on updraft buoyancy. J. Atmos. Sci., 65, 2174-2193.

Brown, A., and Coauthors, 2002: Large-eddy simulation of the diurnal cycle of shallow cumulus convection over land. Quart. J. Roy. Meteor. Soc., 128, 1075-1093.

Canut, G., M. Lothon, F. Said, and F. Lohou, 2010: Observation of entrainment at the interface between monsoon flow and the Saharan air layer. Quart. J. Roy. Meteor. Soc., 136, 34-46, doi:10.1002/qj.471. 
Chen, F., and Coauthors, 2007: Description and evaluation of the characteristics of the NCAR high-resolution land data assimilation system. J. Appl. Meteor. Climatol., 46 (6), 694-713.

Conzemius, R. J., and E. Fedorovich, 2006: Dynamics of sheared convective boundary layer entrainment. Part I: Methodological background and large-eddy simulations. J. Atmos. Sci., 63, 1151-1178.

Courant, R., K. Friedrichs, and H. Lewy, 1967: On the partial difference equations of mathematical physics. IBM J. Res. Develop., 11, 215-234.

Courault, D., P. Drobinski, Y. Brunet, P. Lacarrere, and C. Talbot, 2007: Impact of surface heterogeneity on a buoyancy-driven convective boundary layer in light winds. Bound.-Layer Meteor., 124, 383-403, doi:10.1007/s10546-007-9172-y.

Deardorff, J. W., 1970: A three-dimensional numerical investigation of the idealized planetary boundary layer. Geophys. Fluid Dyn., 1, 377-410, doi:10.1080/03091927009365780.

_ 1980 : Stratocumulus-capped mixed layers derived from a three-dimensional model. Bound.-Layer Meteor., 18, 495-527.

— G. E. Willis, and B. H. Stockton, 1980: Laboratory studies of the entrainment zone of a convectively mixed layer. J. Fluid Mech., 100, 41-64.

Fernando, H. J. S., 1991: Turbulent mixing in stratified fluids. Annu. Rev. Fluid Mech., 23, 455-493.

Gentine, P., D. Entekhabi, and J. Polcher, 2010: Spectral behaviour of a coupled land-surface and boundary-layer system. Bound.-Layer Meteor., 134, 157-180, doi:10.1007/ s10546-009-9433-z.

$\ldots, \ldots$, and _ 2011a: The diurnal behavior of evaporative fraction in the soil-vegetation-atmospheric boundary layer continuum. J. Hydrometeor., 12, 1530-1546.

_ _ J. Polcher, and D. Entekhabi, 2011b: Harmonic propagation of variability in surface energy balance within a coupled soilvegetation-atmosphere system. Water Resour. Res., 47, W05525, doi:10.1029/2010WR009268.

— A. K. Betts, B. R. Lintner, K. L. Findell, C. C. van Heerwaarden, and F. D. Andrea, 2013: A probabilistic bulk model of coupled mixed layer and convection. Part II: Shallow convection case. J. Atmos. Sci., 70, 1557-1576.

Golaz, J.-C., 2001: A large-eddy simulation study of cumulus clouds over land and sensitivity to soil moisture. Atmos. Res., 59-60, 373-392.

Heerwaarden, C. C. V., J. Vilà-Guereau de Arellano, A. F . Moene, and A. A. M. Holtslag, 2009: Interactions between dry-air entrainment, surface evaporation and convective boundarylayer development. Quart. J. Roy. Meteor. Soc., 135, $1277-$ 1291, doi:10.1002/qj.431.

Heus, T., and H. J. J. Jonker, 2008: Subsiding shells around shallow cumulus clouds. J. Atmos. Sci., 65, 1003-1018.

Huang, H.-Y., and S. A. Margulis, 2011: Investigating the impact of soil moisture and atmospheric stability on cloud development and distribution using a coupled large-eddy simulation and land surface model. J. Hydrometeor., 12, 787-804.

- , and - 2013: Impact of soil moisture heterogeneity length scale and gradients on daytime coupled land-cloudy boundary layer interactions. Hydrol. Processes, 27, 1988-2003, doi:10.1002/hyp.9351.

Jiang, H., and G. Feingold, 2006: Effect of aerosol on warm convective clouds: Aerosol-cloud-surface flux feedbacks in a new coupled large eddy model. J. Geophys. Res., 111, 1-12, doi:10.1029/2005JD006138.

Jonker, H. J. J., M. van Reeuwijk, P. P. Sullivan, and E. G. Patton, 2012: Interfacial layers in atmospheric clear and cloudy boundary layers. Proc. Seventh Int. Symp. on Turbulence, Heat and Mass Transfer, Palermo, Italy, International Centre for Heat and Mass Transfer, 1-12.

Joseph, J. H., W. J. Wiscombe, and J. A. Weinman, 1976: The deltaEddington approximation for radiative flux transfer. J. Atmos. Sci., 33, 2452-2459.

Kustas, W. P., and C. S. Daughtry, 1990: Estimation of the soil heat flux/net radiation ratio from spectral data. Agric. For. Meteor., 49, 205-223, doi:10.1016/0168-1923(90)90033-3.

LeMone, M. A., and W. T. Pennell, 1976: The relationship of trade wind cumulus distribution to subcloud layer fluxes and structure. Mon. Wea. Rev., 104, 524-539.

Lewellen, D. C., and W. S. Lewellen, 1996: Influence of Bowen ratio on boundary-layer cloud structure. J. Atmos. Sci., 53, 175-187.

— cloudy boundary layers. J. Atmos. Sci., 59, 2966-2986.

Lohou, F., B. Campistron, A. Druilhet, P. Foster, and J. P. Pages, 1998: Turbulence and coherent organizations in the atmospheric boundary layer: A radar-aircraft experimental approach. Bound.-Layer Meteor., 86, 147-179.

— , F. Saïd, M. Lothon, P. Durand, and D. Serça, 2010: Impact of boundary-layer processes on near-surface turbulence within the West African monsoon. Bound.-Layer Meteor., 136, 1-23, doi:10.1007/s10546-010-9493-0.

Moeng, C.-H., 1998: Stratocumulus-topped atmospheric planetary boundary layer. Buoyant Convection in Geophysical Flows, E. J. Plate et al., Eds., Kluwer Academic, 421-440.

- 2000: Entrainment rate, cloud fraction, and liquid water path of PBL stratocumulus clouds. J. Atmos. Sci., 57, 36273643.

Monteith, J. L., 1981: Evaporation and surface temperature. Quart. J. Roy. Meteor. Soc., 107, 1-27, doi:10.1002/qj.49710745102.

Nicholls, S., and M. A. LeMone, 1980: The fair weather boundary layer in GATE: The relationship of subcloud fluxes and structure to the distribution and enhancement of cumulus clouds. J. Atmos. Sci., 37, 2051-2067.

, - _ and G. Sommeria, 1982: The simulation of a fair weather marine boundary layer in GATE using a threedimensional model. Quart. J. Roy. Meteor. Soc., 108, 167-190.

Otles, Z., and J. A. Young, 1996: Influence of shallow cumuli on subcloud turbulent fluxes analyzed from aircraft data. $J$. Atmos. Sci., 53, 665-676.

Patton, E. G., P. P. Sullivan, and C.-H. Moeng, 2005: The influence of idealized heterogeneity on wet and dry planetary boundary layers coupled to the land surface. J. Atmos. Sci., 62, 2078-2097.

Penman, H. L., 1948: Natural evaporation from open water, bare soil and grass. Proc. Roy. Soc. London, 193A, 120-145.

Pino, D., J. Vilà-Guereau de Arellano, and P. J. Duynkerke, 2003: The contribution of shear to the evolution of a convective boundary layer. J. Atmos. Sci., 60, 1913-1926.

Raasch, S., and G. Harbusch, 2001: An analysis of secondary circulations and their effects caused by small-scale surface inhomogeneities using large-eddy simulation. Bound.-Layer Meteor., 101, 31-59, doi:10.1023/A:1019297504109.

Santanello, J. A., and M. A. Friedl, 2003: Diurnal covariation in soil heat flux and net radiation. J. Appl. Meteor., 42, 851-862.

Schumann, U., A. Dörnbrack, and B. Mayer, 2002: Cloud-shadow effects on the structure of the convective boundary layer. $M e$ teor. Z., 11, 285-294, doi:10.1127/0941-2948/2002/0011-0285.

Siebesma, A. P., 1998: Shallow cumulus convection. Buoyant Convection in Geophysical Flows, E. J. Plate et al., Eds., Kluwer Academic, 441-486. 
and Coauthors, 2003: A large eddy simulation intercomparison study of shallow cumulus convection. J. Atmos. Sci., 60, 1201-1219.

Small, E. E., and S. A. Kurc, 2003: Tight coupling between soil moisture and the surface radiation budget in semiarid environments: Implications for land-atmosphere interactions. Water Resour. Res., 39, 1278, doi:10.1029/2002WR001297.

Soares, P. M. M., P. M. A. Miranda, P. A. Siebesma, and J. Teixeira, 2004: An eddy-diffusivity/mass-flux parametrization for dry and shallow cumulus convection. Quart. J. Roy. Meteor. Soc., 8, 3365-3383, doi:10.1256/qj.03.223.

Stechmann, S. N., and B. Stevens, 2010: Multiscale models for cumulus cloud dynamics. J. Atmos. Sci., 67, 32693285 .

Stephens, G. L., 1984: Review: The parameterization of radius for numerical weather prediction and climate models. Mon. Wea. Rev., 112, 826-867.

Stevens, B., 2005: Atmospheric moist convection. Annu. Rev. Earth Planet. Sci., 33, 605-643, doi:10.1146/annurev.earth.33.092203.122658.

- 2007: On the growth of layers of nonprecipitating cumulus convection. J. Atmos. Sci., 64, 2916-2931.

Stull, R. B., 1988: An Introduction to Boundary Layer Meteorology. Kluwer Academic, 666 pp.

Sullivan, P. P., and E. G. Patton, 2011: The effect of mesh resolution on convective boundary layer statistics and structures generated by large-eddy simulation. J. Atmos. Sci., 68, 23952415.

, C.-H. Moeng, B. Stevens, D. H. Lenschow, and S. D. Mayor, 1998: Structure of the entrainment zone capping the convective atmospheric boundary layer. J. Atmos. Sci., 55, 30423064 .
Taylor, C. M., R. A. M. de Jeu, F. Guichard, P. P. Harris, and W. A. Dorigo, 2012: Afternoon rain more likely over drier soils. Nature, 489, 423-426, doi:10.1038/nature11377.

Tiedtke, M., 1989: A comprehensive mass flux scheme for cumulus parameterization in large-scale models. Mon. Wea. Rev., 117, 1779-1800.

_ - W. Heckley, and J. Slingo, 1988: Tropical forecasting at ECMWF: The influence of physical parametrization on the mean structure of forecasts and analyses. Quart. J. Roy. Meteor. Soc., 114, 639-664.

Urankar, G., T. V. Prabha, G. Pandithurai, P. Pallavi, D. Achuthavarier, and B. N. Goswami, 2012: Aerosol and cloud feedbacks on surface energy balance over selected regions of the Indian subcontinent. J. Geophys. Res., 117, D04210, doi:10.1029/2011JD016363.

van Heerwaarden, C. C., J. Vilà-Guerau de Arellano, A. Gounou, F. Guichard, and F. Couvreux, 2010: Understanding the daily cycle of evapotranspiration: A method to quantify the influence of forcings and feedbacks. J. Hydrometeor., 11, 1405-1422.

Wang, K., R. E. Dickinson, and S. Liang, 2008: Observational evidence on the effects of clouds and aerosols on net ecosystem exchange and evapotranspiration. Geophys. Res. Lett., 35, L10401, doi:10.1029/2008GL034167.

Zhao, M., and P. H. Austin, 2005a: Life cycle of numerically simulated shallow cumulus clouds. Part I: Transport. J. Atmos. Sci., 62, 1269-1290.

$\longrightarrow$, and $-2005 \mathrm{~b}$ : Life cycle of numerically simulated shallow cumulus clouds. Part II: Mixing dynamics. J. Atmos. Sci., 62, 1291-1310.

Zhu, P., and B. Albrecht, 2003: Large eddy simulations of continental shallow cumulus convection. J. Geophys. Res., 108, 4453, doi:10.1029/2002JD003119. 